\title{
Intrinsic Circuit Organization and Theta-Gamma Oscillation Dynamics in the Entorhinal Cortex of the Rat
}

\author{
Pascale Quilichini, ${ }^{1,2}$ Anton Sirota, ${ }^{1,3}$ and György Buzsáki ${ }^{1}$ \\ ${ }^{1}$ Center for Molecular and Behavioral Neuroscience, Rutgers, The State University of New Jersey, Newark, New Jersey 07102, ${ }^{2}$ Inserm, Unité Mixte de \\ Recherche 751, Faculté de Médecine La Timone, 13385 Marseille, France, and ${ }^{3}$ Center for Integrative Neuroscience, University of Tübingen, 72076 \\ Tübingen, Germany
}

\begin{abstract}
A thorough knowledge of the intrinsic circuit properties of the entorhinal cortex (EC) and the temporal dynamics these circuits support is essential for understanding how information is exchanged between the hippocampus and neocortex. Using intracellular and extracellular recordings in the anesthetized rat and anatomical reconstruction of single cells, we found that EC5 and EC2 principal neurons form large axonal networks mainly within their layers, interconnected by the more vertically organized axon trees of EC3 pyramidal cells. Principal cells showed layer-specific unique membrane properties and contributed differentially to theta and gamma oscillations. EC2 principal cells were most strongly phase modulated by EC theta. The multiple gamma oscillators, present in the various EC layers, were temporally coordinated by the phase of theta waves. Putative interneurons in all EC layers fired relatively synchronously within the theta cycle, coinciding with the maximum power of gamma oscillation. The special wiring architecture and unique membrane properties of EC neurons may underlie their behaviorally distinct firing patterns in the waking animal.
\end{abstract}

\section{Introduction}

The entorhinal cortex (EC) is the major input-output partner structure of the hippocampus (Van Hoesen and Pandya, 1975; Burwell, 2000; Squire, 2004; Suzuki and Amaral, 2004). The recent discovery of "grid cells" has rekindled interest in the physiological and anatomical studies of the EC (Hafting et al., 2005; Moser et al., 2008). A subset of superficial neurons, mainly in layer II (EC2), of the dorsocaudal medial EC form a topographically organized neural map of the spatial environment. In addition to these grid cells, "border cells," distributed in all layers (Solstad et al., 2008), "head direction cells" (Ranck, 1985; Taube, 1995), and "conjunctive cells" of position and head direction information are present in EC3 and EC5 (Sargolini et al., 2006) and form the basis of a general navigation system (Moser et al., 2008). The emergence of these layer-dependent representations has been linked to the intrinsic connectivity of the EC and the theta-gamma oscillatory dynamic they support (McNaughton et al., 2006; Witter and Moser, 2006; Burgess et al., 2007; Hasselmo et al., 2007; Blair et al., 2008; Jeewajee et al., 2008; Moser et al., 2008). However, neither the intrinsic anatomical organization of the EC nor the contribution of circuits to the various oscillatory rhythms is well understood (Kloosterman et al., 2003, 2004; Witter and Moser, 2006).

Received Feb. 17, 2010; revised May 12, 2010; accepted June 13, 2010.

This work was supported by National Institutes of Health Grants NS034994 and MH54671, the J. D. McDonnell Foundation, the International Brain Research Organization, the Fondation pour la Recherche Médicale, the Philippe Foundation, and the Epilepsy Foundation of America. We thank Kenji Mizuseki, Edvard Moser, Miles Whittington, and Menno Witter for their comments on this manuscript.

Correspondence should be addressed to György Buzsáki, Center for Molecular and Behavioral Neuroscience, Rutgers University, 197 University Avenue, Newark, NJ 07102. E-mail: buzsaki@axon.rutgers.edu.

DOI:10.1523/JNEUROSCI.1327-10.2010

Copyright $\odot 2010$ the authors $\quad 0270-6474 / 10 / 3011128-15 \$ 15.00 / 0$
EC2 principal neurons (mainly stellate cells) (Klink and Alonso, 1997) have long been considered a key contributor to theta rhythm generation because they are endowed with intrinsic properties to oscillate at theta frequency, mainly attributable to the high density of HCN1 channels in these cells (Alonso and Llinás, 1989; Giocomo et al., 2007; Giocomo and Hasselmo, 2009) and because removal of the EC inputs dramatically affects hippocampal theta oscillations (Buzsáki et al., 1983; Bragin et al., 1995). However, how theta oscillations are organized in the various layers of the EC is not well understood (Mizuseki et al., 2009). EC theta also significantly modulates the power of locally generated gamma oscillations, allowing for a temporal coordination of layer-specific computations (Chrobak and Buzsáki, 1998; Buzsáki et al., 2002; Cunningham et al., 2003; Dickson et al., 2003; Mormann et al., 2005; Steinvorth et al., 2010). The importance of EC computation is suggested by the observation that EC2 grid cells show phase advancement of their spikes relative to the theta cycle when the rat runs through the receptive field of the neurons (Hafting et al., 2008; Mizuseki et al., 2009). Generation of the grid pattern is assumed to require self-sustained activity in networks with extensive recurrent connectivity (Fuhs and Touretzky, 2006; McNaughton et al., 2006; Burgess et al., 2007; Hasselmo et al., 2007; Hasselmo, 2008; Burak and Fiete, 2009). A requisite for understanding how the functional neuron types in EC and their interactions generate network patterns requires knowledge about their local and interlaminar connectivity (Witter and Moser, 2006). To address these issues, we have performed intracellular recordings from EC2, EC3, and EC5 principal cells in the anesthetized rat and identified their theta and gamma oscillation patterns in relation to simultaneously recorded extracellular local field potentials (LFPs) and multiple single-unit activity. 


\section{Materials and Methods}

Animal surgery. Experiments were performed on 39 male Sprague Dawley rats (250-400 g; Hilltop Laboratories), which were anesthetized with urethane (1.5 g/kg, i.p.) and ketamine/xylazine (20 and $2 \mathrm{mg} / \mathrm{kg}$, i.m.). Additional doses of ketamine/xylazine ( 2 and $0.2 \mathrm{mg} / \mathrm{kg}$ ) were given as needed. The body temperature was monitored and kept constant with a heating pad. The heart rate, breathing rate, and the arterial oxygen saturation were also monitored with an oximeter (MouseOX; StarrLife Science Corp.) during the entire duration of the experiment. The head was placed in a stereotaxic frame, the skull was exposed, and a small hole (1.2 $\mathrm{mm}$ in diameter) was drilled above the visual cortex V1 [anterior (A), $-7.0 \mathrm{~mm}$ from the bregma; lateral (L), $4.0 \mathrm{~mm}$ from the midline; dorsal (D), 5.0-5.2 mm from brain surface] through which an extracellular recording silicon probe was inserted at a $20^{\circ}$ angle caudally to target the dorsomedial portion of entorhinal cortex. Another hole was drilled above the ipsilateral visual cortex V2 (A, $9.0 \mathrm{~mm}$;, $4.0 \mathrm{~mm}$; D, 3.5-4.5 $\mathrm{mm}$ from the brain surface) to insert an intracellular electrode vertically close to the extracellular electrode (see Fig. 4A). Two miniature stainlesssteel screws were driven into the skull and served as ground and reference electrodes, respectively, for extracellular recordings. $\mathrm{An} \mathrm{Ag}-\mathrm{AgCl}$ wire, placed in the neck muscles, served as a reference electrode for intracellular recordings. The skull holes were covered with paraffin-wax mixture after electrode insertion (Henze et al., 2000). All experiments were performed in accordance with experimental guidelines approved by the Rutgers University Animal Care and Use Committee.

Electrophysiological methods. Extracellular signal was amplified $(1000 \times)$ and bandpass filtered $(1 \mathrm{~Hz}$ to $5 \mathrm{kHz})$ by a multichannel alternating current amplifier (Sensorium EPA5; Sensorium Inc.). The intracellular signals were amplified with a direct current amplifier (Axoprobe 1A; Molecular Devices). Wide-band extracellular and intracellular signals were digitized at $20 \mathrm{kHz}$ and stored for offline analysis (64 channels DataMax System, 16-bit resolution; RC Electronics). The extracellular recordings were performed by either a four-shank silicon probe (32 sites distributed at $20 \mu \mathrm{m}$ intervals; NeuroNexus Technologies) placed in EC2-EC3 or EC3-EC5 or a single-shank silicon probe (Acreo) with 32 linearly arranged recording sites (at $50 \mu \mathrm{m}$ intervals) placed almost perpendicular to the layers of the dorsomedial entorhinal cortex (see Fig. $4 \mathrm{~A}$ ). Online positioning of the electrodes was assisted by the presence of unit activity in cell body layers and the reversal of theta $(3-6 \mathrm{~Hz})$ oscillations when passing from EC2 to EC1 (Chrobak and Buzsáki, 1998; Mizuseki et al., 2009), and their final positions were confirmed histologically after the experiment. Only experiments with appropriate position of the probe were used for analysis. To facilitate anatomical localization of the track, DiI was applied on the back of the probe shank(s) before insertion.

Intracellular penetrations were performed with sharp glass capillaries, pulled from borosilicate glass tubes, and filled with $1.5 \mathrm{M} \mathrm{K}$-acetate and $2 \%$ biocytin, pH 7.4 (40-62 M $\Omega$ ). After the membrane potential became stable, brief hyperpolarizing and depolarizing current steps were injected through the electrode to characterize membrane potential properties (from -0.5 to $0.5 \mathrm{nA}, 500 \mathrm{~ms}$ ). Only healthy neurons (input resistance $>20 \mathrm{M} \Omega$; resting membrane potential less than $-55 \mathrm{mV}$ and overshooting action potentials) were included for analysis. At the end of the physiological data collection, biocytin was loaded into the recorded neuron by positive current pulses $(+0.5 \mathrm{nA}, 500 \mathrm{~ms}$ at $1 \mathrm{~Hz}$ for $5-25 \mathrm{~min})$.

Data analysis. Raw data were preprocessed using a custom-developed suite of programs (Csicsvari et al., 1999). The wide-band signal was downsampled to $1250 \mathrm{~Hz}$ for LFP signal analysis. Single units were isolated from the wide-band signal semiautomatically by the customdeveloped clustering analysis program KlustaKwik (http://klustakwik. sourceforge.net/) (Harris et al., 2002) and refined manually using custom-made software (http://klusters.sourceforge.net; http://neuroscope. sourceforge.net) (Hazan et al., 2006). Only units showing a clear refractory period and well defined cluster boundaries were included for analysis. For the separation of putative principal cells and interneurons, we took advantage of the simultaneously recorded cells to assess putative monosynaptic connections among neurons from their cross-correlograms (Barthó et al., 2004; Sirota et al., 2008; Mizuseki et al., 2009). To test for significance of the peaks and troughs in the unit crosscorrelograms, a nonparametric significance test, based on jittering of spike trains, was used (Fujisawa et al., 2008). In short, the referred pointprocess dataset was jittered $([-5,+5]$ ms interval) to produce 1000 surrogate cross-correlograms from which the exact $p$ value for each time bin was computed over the $[-30,+30] \mathrm{ms}$ interval. For each crosscorrelogram, global bands at an acceptance level $99 \%$ were created from the maximum and minimum of each jitter surrogate cross-correlogram across the interval $[-30,+30]$ ms. Time bins with $p \leq 0.01$ were considered significant for short latency peaks (or troughs; $1-5 \mathrm{~ms}$ ) in the original cross-correlogram when at least one bin was atypical with respect to the upper (or lower) global band. The significant bin effects were considered to be attributable to excitation or inhibition of the reference unit by the referred unit (Fujisawa et al., 2008). For cell pairs recorded from the same shank, the $0-1 \mathrm{~ms}$ bin was not considered because our clustering program cannot resolve superimposed spikes. The cluster properties of the neuron pairs, designated as monosynaptically connected by the statistical analysis, were visually inspected, and spurious cell pairs attributable to potential clustering errors were excluded from additional analysis. Using this method, 456 of the 1100 recorded units were classified as excitatory or inhibitory neurons (see Fig. 8). Only this physiologically defined subgroup was included for quantitative analyses. Layer assignment of the neurons was determined from the approximate location of their somata relative to the recordings sites (with the largestamplitude unit corresponding to the putative location of the soma), the known distances between the recording sites, and the histological reconstruction of the recording electrode tracks (see Fig. 4A).

Recording sessions were divided into brain states of theta and slow oscillation periods. LFP theta epochs were visually selected from the raw traces, assisted by the ratios of the whitened power in the theta band (3-6 $\mathrm{Hz}$ ) and the power of the neighboring bands (1-3 and 7-14 Hz) of EC3 LFPs (see Fig. 4D). Spectral analyses were performed using direct multitaper estimates (Mitra and Pesaran, 1999; Sirota et al., 2008). Typically, window sizes of 2-4s and three to five tapers were used. The theta phase of the EC3 LFP was determined from the LFP filtered in the theta band (adjusted for the dominant theta frequency in each experiment, typically $\sim 2-6 \mathrm{~Hz}$ ). The instantaneous phase was computed as the angle of the Hilbert transform, and the distribution of the phases in each session was tested for uniformity before unit analysis. Using linear interpolation, a value of phase was assigned to each action potential (units and intracellular spikes).

To establish the gamma-phase modulation of units, the gamma bursts in EC3 during theta epochs were detected (Sirota et al., 2008) and the instantaneous phase of gamma oscillation was estimated by Hilbert transform of the $30-90 \mathrm{~Hz}$ filtered signal. Only neurons with at least 50 spikes and a firing rate $>0.5 \mathrm{~Hz}$ during the theta epochs were included for the LFP unit analysis. The theta and gamma phase modulation of action potentials was determined by Rayleigh circular statistics (Fisher, 1993); $p<0.05$ was considered significant. Group comparison tests of circular variables were performed using circular ANOVA.

Coherence between the intracellular membrane potential $\left(V_{\mathrm{m}}\right)$ and instantaneous LFP theta was computed using the EC3 LFP signal because recordings from this layer were available in all experiments. For the analyses of $V_{\mathrm{m}}$ fluctuations, the intracellular action potentials $(3 \mathrm{~ms}$ ) were removed and replaced by interpolated values. Spectral power of $V_{\mathrm{m}}$ was computed, and the relative power coefficient (ratio of the peak power and the SD across all frequencies) was used to characterize the strength of the dominant frequency of theta oscillation.

The phase and power relationship between $V_{\mathrm{m}}$ and the LFP signal was assessed by spectral methods (Isomura et al., 2006). For the assessment of $V_{\mathrm{m}}$ power-LFP power relationship, the correlation coefficient between normalized spectral power values of the respective signals ( $V_{\mathrm{m}}$ and LFP) at all pairs of frequencies was calculated ("comodugram").

The magnitude of theta phase modulation of gamma power $(30-90$ $\mathrm{Hz})$ and of the high frequencies $(>200 \mathrm{~Hz})$ was estimated by calculating the power of the gamma/fast frequency band in short (50-100 ms) overlapping windows at all the recording sites and correlating the power with the instantaneous phase of theta, obtained from the Hilbert transformation of the filtered signal from EC3 (see Fig. 11E). 



Figure 1. Anatomical properties of $\mathrm{EC}$ principal neurons. Three-dimensional reconstruction of the dendrites (yellow) and axon arbor (red) of in vivo filled EC2 stellate neuron and $\mathrm{EC} 3$ and $\mathrm{EC5}$ pyramidal cells. Each reconstruction was drawn from successive sagittal sections, the outlines of which are indicated by gray lines (top row). Bottom row, Superimposed ( $n=56,23$, and 51 for EC2, EC3, and EC5 neurons, respectively) sections to illustrate the layer distribution of dendrites and axons. WM, White matter. Note that most axon collaterals of the EC2 stellate neuron are confined to $E C 1$, the axon tree of the EC5 cell occupies mostly EC5 and EC3, whereas the relatively sparse axon collaterals of the EC3 neuron span nearly equally all layers.

Current source density (CSD) analysis of the simultaneously recorded field potentials was used to eliminate volume conduction and localize synaptic currents. CSD was computed as the second spatial derivative of the recorded LFPs and smoothed spatially with a triangular kernel (Freeman and Nicholson, 1975). Activity from malfunctioning sites was interpolated from the neighboring sites.

Histological processing. Under deep urethane anesthesia, the animals were perfused intracardially with $100 \mathrm{ml}$ of cold saline, followed by $250-$ $300 \mathrm{ml}$ of $4 \%$ paraformaldehyde in $0.1 \mathrm{~m}$ phosphate buffer (PB), $\mathrm{pH}$ 7.4. The brains were removed and postfixed at $4^{\circ} \mathrm{C}$ overnight. They were then rinsed in PBS, cryoprotected in $20 \%$ sucrose in PB for $24 \mathrm{~h}$, and quickly frozen on dry ice. The brains were sliced into $40-\mu \mathrm{m}$-thick parasagittal sections by a Vibratome (Leica). The biocytin-loaded neurons were labeled in serial sections by the avidin-biotin-HRP complex (Vector Laboratories) method. The sections were mounted on gelatin-coated glass slides and counterstained with thionin (see Fig. 2). The labeled neurons were reconstructed from multiple serial sections with NeuroLucida (MicroBrightField), together with the tracks of the extracellular silicon probes. In each section, the processes (dendrites and/or axons) were traced taking into account their depth in the section. In addition, the contours of the cortical layers were outlined (see Fig. 1). The NeuroLucida software was used to quantify the length and pattern of the dendritic and axonal processes in the three dimensions. For each cell, the total number of boutons was estimated from a partial count of boutons over a 200-600 $\mu \mathrm{m}$ axon segment in each layer, using a $100 \times$ oil-immersed objective. The bouton density was calculated as the number of boutons per $100 \mu \mathrm{m}$ axonal segment. All measurements were corrected for an estimated $20 \%$ tissue shrinkage.

\section{Results}

Dendritic and axonal arborization of EC principal neurons

We have obtained stable intracellular recordings from eight layer II (EC2), 15 layer III (EC3), and 12 layer V (EC5) histologically verified neurons of the dorsomedial entorhinal cortex. The soma size, dendritic morphology, and layer distribution of dendritic branches were similar to those described previously both in vitro and in vivo (supplemental Table 1, supplemental Fig. 1, available at www.jneurosci.org as supplemental material) (Germroth et al., 1989; Lingenhöhl and Finch, 1991; Alonso and Klink, 1993; Tamamaki and Nojyo 1993; Klink and Alonso, 1997; van der Linden and Lopes da Silva 1998; Dickson et al., 2000). Therefore, our description of the neurons focuses mainly on their threedimensional axon arborization within the EC. For detailed anatomical analyses, we have chosen two EC2, two EC3, and an EC5 cell on the basis of their extensive axonal arborizations.

\section{EC2 stellate cells}

The star-shaped arborization and spanning of the dendritic tree of all intracellularly recorded EC2 neurons characterized them as stellate neurons. The multiple basal dendrites were distributed in EC2 and EC3 layers, whereas the apical dendrites spanned EC1 and EC2. Multiple apical and basal branches arose from the soma and all dendrites were covered with small dendritic spines. 

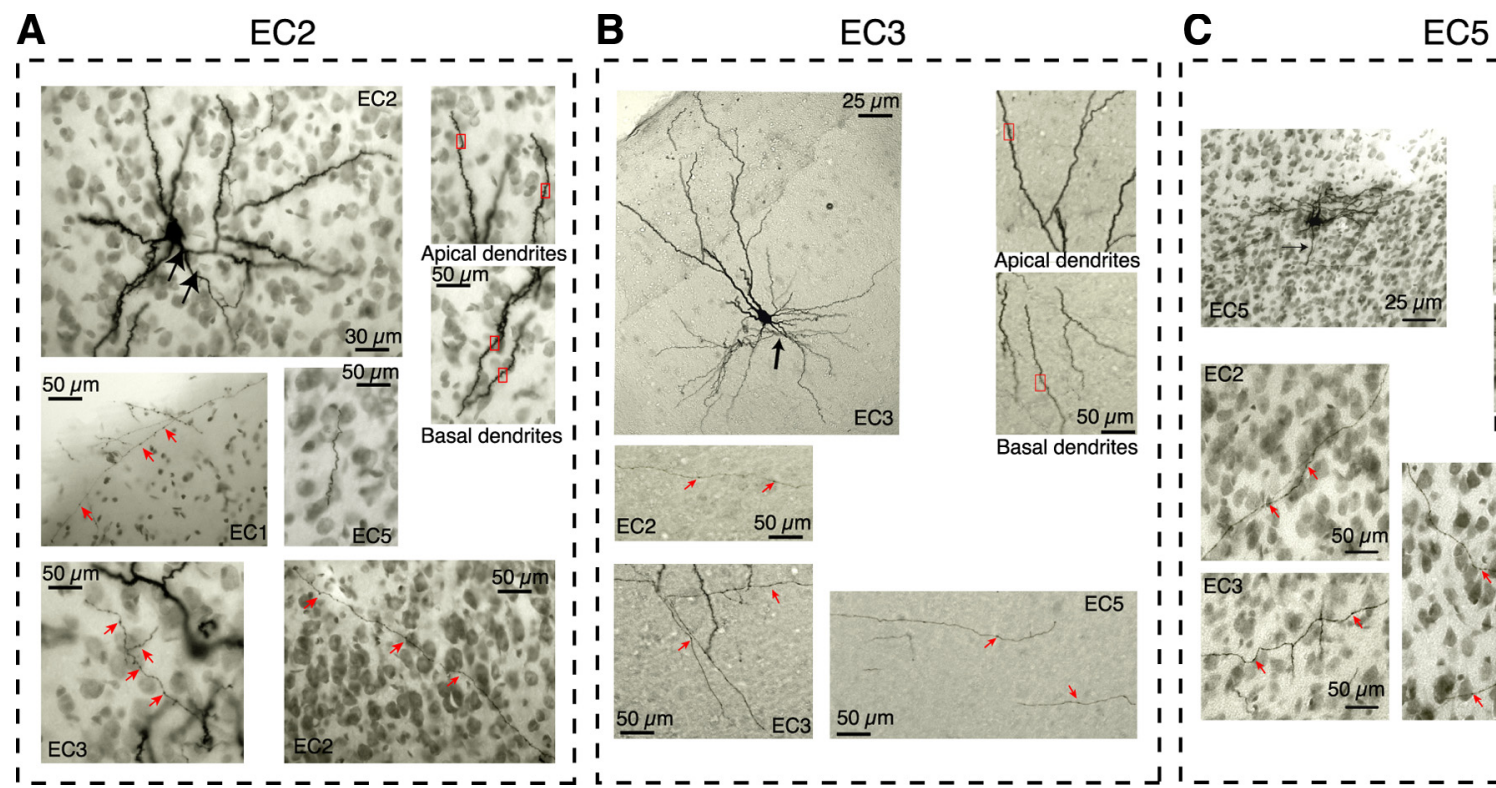

Figure 2. Dendritic and axonal details of example EC2, EC3, and EC5 neurons. Morphological details of in vivo biocytin-filled EC2 stellate neuron $(\boldsymbol{A}), \mathrm{EC}(\boldsymbol{B})$, and EC5 (C) pyramidal cells on a Nissl-stained background. The black arrow points to the emergence of the axon. Boutons are indicated by red arrows. The apical and basal dendrites are also magnified. Red boxes enclose spines.
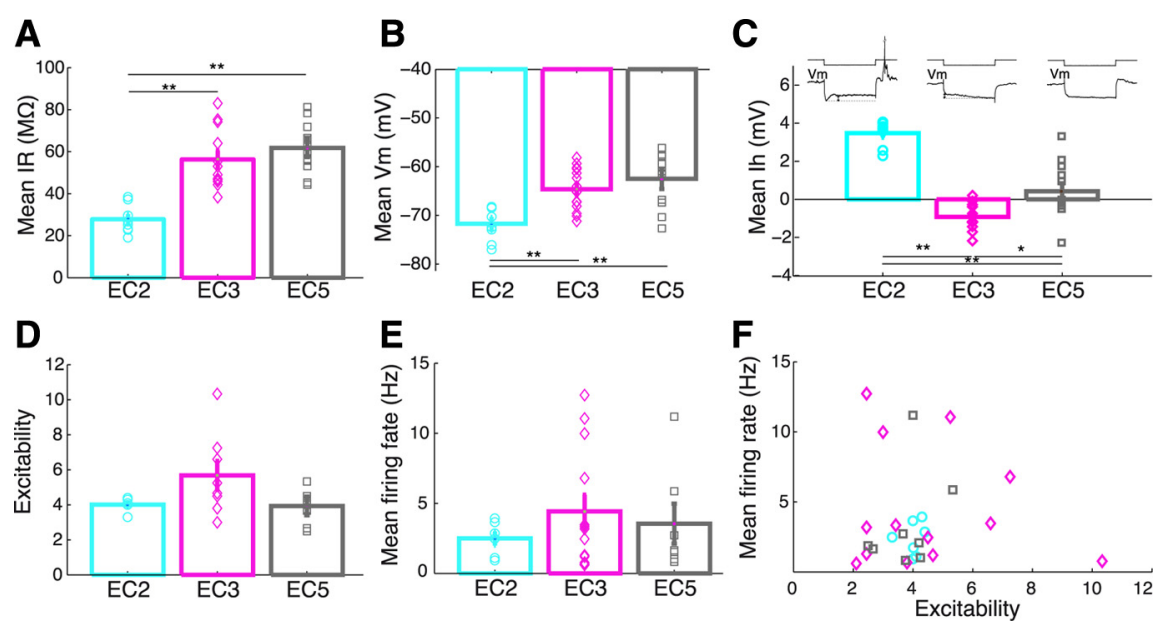

Figure 3. Biophysical properties of $E\left(\right.$ principal neurons in vivo. Input resistance $(\boldsymbol{A} ; \mathrm{IR})$, mean $V_{\mathrm{m}}(\boldsymbol{B})$, and $I_{\mathrm{h}}(\boldsymbol{C})$ of $E(2$ principal cells. The inset in (shows example responses to hyperpolarizing current steps $(-0.2 \mathrm{nA}, 500 \mathrm{~ms})$, showing a sag (inward rectifying current) in the EC2 cell. $\boldsymbol{D}$, Excitability, defined as the number of spikes to depolarizing neurons (0.5 nA, 500 ms pulses); $\boldsymbol{E}$, spontaneous firing rate of the neurons. $F$, Lack of a relationship between excitability and spontaneous firing rate. Note the smallest variability of EC2 neurons in all measures. Layer- and region-specific color coding applies to all figures.

The axonal arborization of EC2-705302 (neuron EC2 \#705302) and EC2-609291 stellate cells were reconstructed from 56 and 37 sagittal sections, respectively, spanning 1823 and $1626 \mu \mathrm{m}$ in the frontocaudal axis. The main axon ramified close to the soma in EC2 and gave rise to many collaterals. A thick projecting axon was followed to the white matter but could not be traced further, mostly likely because of the short postinjection survival interval (Tamamaki and Nojyo, 1993). The three-dimensional extent of neuron EC2-705203 is shown in Figure 1 (see also supplemental Fig. 1, available at www.jneurosci.org as supplemental material). The total axonal length of this stellate cell was $28,419 \mu \mathrm{m}$ (EC2$609291=20,633 \mu \mathrm{m})($ supplemental Table 2, available at www. jneurosci.org as supplemental material). The overwhelming majority of axon collaterals (90.7\%) occupied EC1, in which they formed a bouquet of collaterals oriented mainly parallel to the layer. Many long branches stretched in the mediolateral orienta- tion, occupying the entire width of EC1 from the pia to EC2. This dense axonal arbor spanned $1280 \mu \mathrm{m}$ in the mediolateral axis and $2266 \mu \mathrm{m}$ in the dorsoventral axis. The remaining minority of axon collaterals was evenly distributed in EC2 and the adjacent EC3 layer. The total number of boutons was 3650, with an average interbouton interval of $8.7 \mu \mathrm{m}$, with the highest density of boutons in EC1 (12.7/ $100 \mu \mathrm{m}$; EC2 $=10.4 / 100 \mu \mathrm{m}$; EC3 = $11.7 / 100 \mu \mathrm{m})$. The layer distribution of axons and bouton density of neuron EC2609291 is shown in supplemental Table 2 (available at www.jneurosci.org as supplemental material) (Fig. 2) (supplemental Fig. 1, available at www.jneurosci.org as supplemental material). The axon tree of the remaining stellate cells was qualitatively similar but less extensive, likely because of less complete filling of the neurons.

EC3 pyramidal cells

The multiple basal dendrites of EC3 pyramidal cells arose from the soma and distributed in EC3. The apical dendrites emerged from the soma, arborized in EC2, and branched into segments in EC1 parallel to the border with the pia. Both basal and apical dendrites showed abundant small dendritic spines.

In neurons EC3-60126 and EC3-80604, a thick and smooth branch projected down to deeper layers and the white matter but could not be followed further. The main axon gave rise to many collaterals mainly in EC3, showing two trajectories: some of the branches extended parallel to the layer in the anteroposterior axis, whereas the remaining branches remained in the volume occupied by the dendritic tree, expanding toward the superficial layers. The total axonal length of neuron EC3-60126 was 19,257 $\mu \mathrm{m}$ [Figs. 1 (EC3-80604 = 19,810 $\mu \mathrm{m}), 2]$ (supplemental Table 2 , available at www.jneurosci.org as supplemental material). The 
axon arbor occupied mainly a cylindrical field, extending 1668 $\mu \mathrm{m}$ in the dorsoventral and $520 \mu \mathrm{m}$ in the mediolateral axis, and the branches were distributed more evenly in the different layers than those of EC2 neurons, with a dominance in EC3 and EC5 $(\mathrm{EC} 1=12.9 \% ; \mathrm{EC} 2=18.8 \% ; \mathrm{EC} 3=40.6 \%$; and $\mathrm{EC} 5=27.8 \%)$. The total number of boutons was 2321 , with an average interbouton interval of $10.3 \mu \mathrm{m}$. The total length, the overall distribution of axons, and bouton density in neuron EC3-80604 were essentially the same (supplemental Table 2, available at www. jneurosci.org as supplemental material).

\section{EC5 pyramidal cells}

The multiple basal dendrites of EC5 pyramidal cells arose from the soma and distributed horizontally in EC5. A single apical dendritic shaft pointed toward the pia and split into branches in EC1. All dendrites were covered with a large number of small dendritic spines. The dendrites of the reconstructed neuron (EC5-609202) presented the features of a classical pyramidalshaped EC5 neuron. The total length of the large axon arbor $(88,233 \mu \mathrm{m})$ was reconstructed from 51 coronal sections, spanning $3466 \mu \mathrm{m}$ in the frontocaudal axis (Fig. 1) (supplemental Fig. 1, available at www.jneurosci.org as supplemental material). A thick smooth axon collateral entered the white matter but could not be followed further. Most axon branches were evenly distributed in EC5 (66.1\%), whereas the remaining collaterals $(33.3 \%)$ ramified in EC3. In EC5, the axon arbor extended $2748 \mu \mathrm{m}$ in the dorsoventral and $2044 \mu \mathrm{m}$ in the mediolateral axis. The total number of boutons was largest of all cells $(11,817$ with an average interbouton interval of $8.8 \mu \mathrm{m}$ ) (supplemental Table 2, available at www.jneurosci.org as supplemental material). Axon collaterals of other, nonreconstructed, EC5 neurons were qualitatively similar.

In summary, both EC2 stellate and EC5 pyramidal neurons had extensive axonal branches in both the septotemporal and mediolateral directions. Whereas EC2 neurons targeted mainly the apical dendrites in EC1, EC5 pyramidal cells innervated most strongly layers EC5 and EC3. In contrast, the axon arbor of EC3 cells was spatially more compact and formed a barrel-shaped axon arbor, expanding all layers.

\section{Theta oscillations in EC neurons}

EC2 stellate cells had a significantly lower input resistance $(p<$ $10^{-4}$ and $p<10^{-6}$ vs EC3 and EC5, respectively, ANOVA test) and were significantly more hyperpolarized (Fig. $3 A, B ; p<10^{-3}$ and $p<10^{-3}$, respectively) than EC3 and EC5 cells. In addition, EC2 but not EC3 and EC5 neurons (Dickson et al., 1997) had a prominent depolarizing "sag" $\left(I_{\mathrm{h}}\right)$ (Alonso and Llinás, 1989; Dickson et al., 2000) in response to hyperpolarizing current steps (Fig. 3C). In contrast to EC2 stellate cells, EC3 neurons did not show a sag but, instead, an enhanced slow hyperpolarizing response to hyperpolarizing steps (Fig. $3 C$, top inset). This conductance may explain why EC3 pyramidal cells took a significantly longer time to latch back from the "up" to the "down" state during slow oscillations than other EC principal cells (Isomura et al., 2006). In response to depolarizing pulses ( $0.5 \mathrm{nA})$, neurons in all layers fired approximately the same number of spikes (four to five spikes per $500 \mathrm{~ms}$ pulses) (Fig. 3D). Some neurons fired with bursts and others with relatively regular spikes, but no obvious firing pattern differences were detected across the three groups [but see firing pattern differences in the waking animal (Mizuseki et al., 2009)]. The spontaneous firing rates, computed from theta epochs of the entire recording session, were comparable between the neuron groups (Fig. $3 E$ ). No reliable relationship was found between spontaneous firing rate and currentinduced excitability (Fig. $3 F$ ) or between rate and input resistance, suggesting that firing rates are mainly determined by the network into which the neurons are embedded rather than by their biophysical properties.

The network-related behavior of the three groups was markedly different. The simultaneously recorded extracellular LFP, spanning several layers of the EC by the silicon probe, allowed for an unequivocal classification of the epochs into theta or slow oscillations (Fig. 4). These network patterns alternated spontaneously or the state change was induced by pinching the tail of the rat or by an additional dose of the anesthetic. In the absence of theta oscillations, several EC neurons showed a prominent slow oscillation (0.5-1.5 Hz), consisting of alternating depolarized up states with spikes and hyperpolarized down states (Fig. 4). The voltage difference between up and down states was significantly smaller in EC2 stellate cells than in EC3 and EC5 neurons $(p<$ 0.005 , ANOVA). Although the voltage distribution in both EC3 and EC5 neurons was prominently bimodal, the up-to-down transition was slower in EC3, perhaps because of the slow hyperpolarizing response of the membrane in these cells (Fig. 3C) (Isomura et al., 2006). In contrast, during theta oscillations, the membrane voltage distribution was unimodal in all neurons but the magnitude of theta-related voltage fluctuation was significantly larger in EC2 stellate neurons than in EC3 and EC5 pyramidal cells $(p<0.002)$ (Fig. 5).

Because LFP is generated by the integrated electric dipole moments of the membrane currents of neurons (Buzsáki et al., 2003; Nunez and Srinivasan, 2006), examination of the relationship between LFP and concurrently recorded $V_{\mathrm{m}}$ in identified single neurons can provide information about their contribution to the LFP (Stewart et al., 1992). For these analyses, the action potentials were removed from the intracellular recordings and the missing bins were interpolated (see Materials and Methods) (Isomura et al., 2006). Figure $5 A$ illustrates the activity of representative neurons in each EC layer during theta oscillation. The magnitude of theta-related $V_{\mathrm{m}}$ varied from 0.2 to $6 \mathrm{mV}$ in different cells. EC2 stellate cells showed the largest-amplitude and most coherent membrane potential oscillations with the extracellular LFP theta. The LFP-normalized intracellular theta power was significantly larger in EC2 than in EC3 and EC5 cells (Fig. 5C; $p<0.002$, ANOVA test). As expected, the intracellular and LFP theta power were correlated (Fig. 5D; $p<0.04$ ). In the EC2 group, the LFP theta power negatively correlated with the mean membrane voltage $\left(V_{\mathrm{m}}\right)$ of the neurons (Fig. $5 E ; p<0.04$, EC2 differed significantly from the EC5 group; $p<0.05$, MANOVA). The strongest LFP-intracellular $V_{\mathrm{m}}$ coherence was present in EC2 stellate cells (Fig. $5 F$ ). The magnitude of the coherence was correlated with the intracellular theta power $\left(p<0.05\right.$ for EC2 and $p<10^{-3}$ for all cells) but was independent of the LFP theta power or its frequency (Fig. 5G-I).

In addition to the magnitude of intracellular theta and its coherence to LFP in single neurons, the magnitude of the extracellular current flow also depends on the temporally coherent fluctuation of $V_{\mathrm{m}}$ across neurons (Buzsáki et al., 2003; Logothethis, 2003; Nunez and Srinivasan, 2006). Therefore, we also examined the phase preference of the intracellularly recorded neurons to LFP theta, using three complementary measures: the distribution of the phase difference between LFP and intracellular $\left(V_{\mathrm{m}}\right)$ theta oscillations in single cells, the distribution of preferred phases of single neuron spikes, and theta phase distribution of all spikes in all cells. The three approaches gave similar results (Fig. 6). Both the intracellular theta $\left(V_{\mathrm{m}}\right)$ and spike pref- 

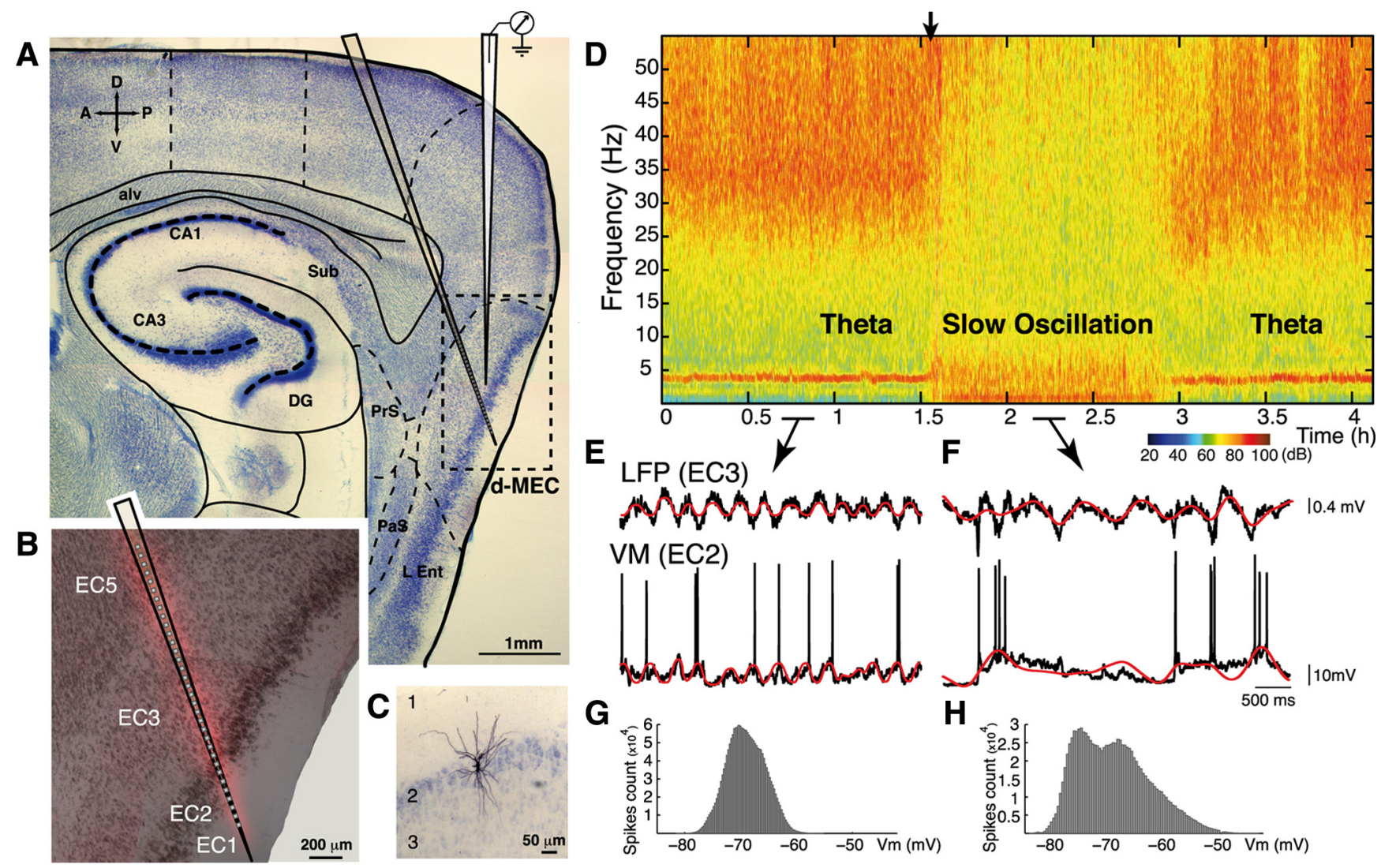

Figure 4. Network patterns in the EC. $A$, Schemata of the intracellular and extracellular (silicon probe; oblique) recordings from the dorsomedial entorhinal cortex (d-MEC). The different regions of the hippocampus, dentate gyrus (DG), subicular complex (Sub, PrS, PaS), and lateral EC (L Ent) are also indicated. alv, Alveus. B, Dil (red)-labeled silicon probe track on a Nissl counterstained section. The 32 recording sites of the probe are also indicated. C, Biocytin-filled EC2 stellate cell from a single Nissl counterstained section. D, Spectrogram of LFP from the EC3 layer of the entorhinal cortex. Arrow, Administration of an additional dose of ketamine/xylazine. Note the sharp 4- $\mathrm{Hz}$-band and gamma-band $(>30 \mathrm{~Hz}$ ) oscillations during theta activity and dominant $\sim 1 \mathrm{~Hz}$ band during slow oscillations. $\boldsymbol{E}, \boldsymbol{F}$, Simultaneously recorded example LFP and intracellular traces during theta $(\boldsymbol{E})$ and slow $(\boldsymbol{F})$ oscillations. Black, Original traces; red, spike-clipped, smoothed traces. $\boldsymbol{G}, \boldsymbol{H}$, Distribution of membrane potential fluctuations during theta and slow oscillations. EC2 cells did not show prominent bimodal up and down states (see also Fig. 1B) (Isomura et al., 2006).

erence of single EC2 neurons showed a relatively narrow phase distribution, close to the trough of EC3 LFP theta. In contrast, neurons in both EC3 and EC5 had a large variability of phase preference (Fig. $6 \mathrm{~A}$ ). Accordingly, the spikes of the EC2 population showed a strong theta modulation with the maximum spiking near the trough of EC3 theta (Fig. 6B). Neurons in the EC3 group were least theta modulated, whereas EC5 cells occupied an intermediate position (Fig. $6 \mathrm{~B}$ ).

In summary, EC2 stellate neurons showed distinct biophysical properties from other EC neurons and displayed largest-amplitude $V_{\mathrm{m}}$ oscillations during theta activity. Furthermore, EC2 stellate cells fired consistently phase-locked to the trough of the EC3 LFP theta, whereas the phase preference and theta entrainment of EC3 and EC5 pyramidal cells were more variable.

\section{Depth profiles of theta, gamma, and high-frequency power} Extracellular LFP was monitored by multiple-site silicon probes. In experiments using the single-shank 32-site probe, depth distribution of the various LFP pattern could be studied quantitatively (Fig. 7). The paucity of unit firing at the most superficial sites identified EC1, with a large increase of spiking activity in EC2. The location of the EC1-EC2 border and the histologically verified track of the probe allowed us to estimate the border between EC3 and EC5. In agreement with previous experiments (Mitchell and Ranck, 1980; Alonso and García-Austt, 1987a,b; Chrobak and Buzsáki, 1998; Cunningham et al., 2003; Hafting et al., 2008), we found a large dip of both theta $(3-5 \mathrm{~Hz})$ and gamma
$(30-60 \mathrm{~Hz})$ power and coherence, relative to the EC3 reference site, and a phase reversal of both theta and gamma rhythms between EC1 and EC2 (Fig. 7A-D). Both theta and gamma LFP were in-phase in EC2-EC5 and highly coherent within EC3. The phase of gamma waves reversed at nearly the same depth as the phase reversal of theta oscillations (Fig. $7 B, C$ ).

In addition to theta and gamma rhythms, the whitened power spectrum also showed a broad "peak" above $100 \mathrm{~Hz}$ (Cunningham et al., 2004; Canolty et al., 2006; Sirota et al., 2008; Colgin et al., 2009). The absolute power of this high-frequency band was only a small fraction of the theta and gamma power and had a relatively uniform power distribution between $150 \mathrm{~Hz}$ and $3 \mathrm{kHz}$. The depth distribution of the high-frequency power was associated with the presence of unit spiking, with very low power in EC1 and highest power at sites with strong unit activity (Cunningham et al., 2004). This high-frequency activity was spatially confined as was evidenced by the fast decrease of coherence values with distance (Fig. 7D), independent of the chosen reference site. The spatial extent of the coherence in the highfrequency band corresponded to the span of the extracellularly recordable action potentials from the same neurons (Henze et al., 2000). These findings suggest that the high-frequency pattern primarily reflects spectral properties of action potentials, most likely summed spike afterpotentials rather than genuine oscillations.

CSD analysis of theta oscillations revealed a strong sink in the deeper part of EC1 (Fig. 7B, S1) and weaker sinks in the superficial and deeper parts of EC3 (Fig. 7B, S2, S3). The strongest sink 
A

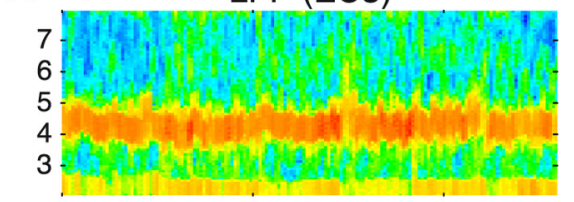

EC2 $(\mathrm{Vm})$

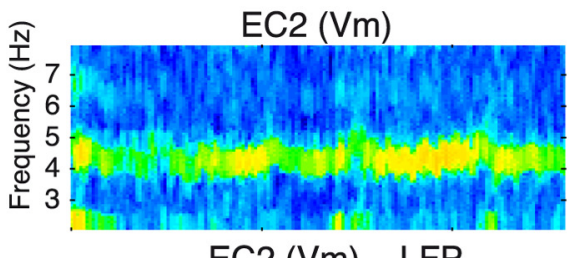

EC2 $(V m)-L F P$

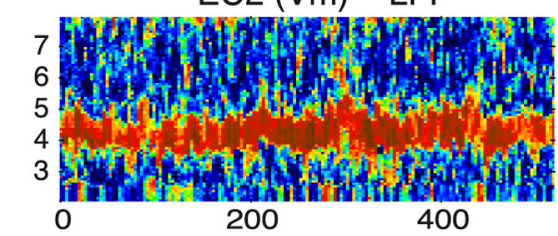

LFP (EC3)

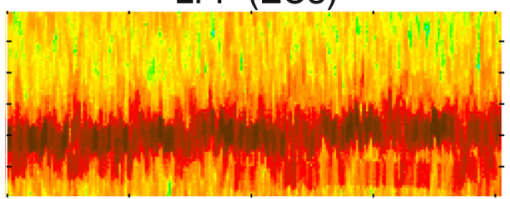

EC3 (Vm)

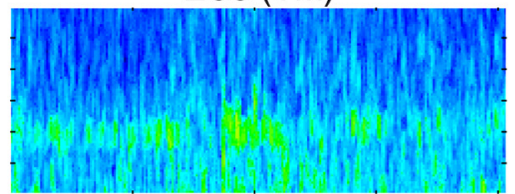

EC3 $(V m)-L F P$

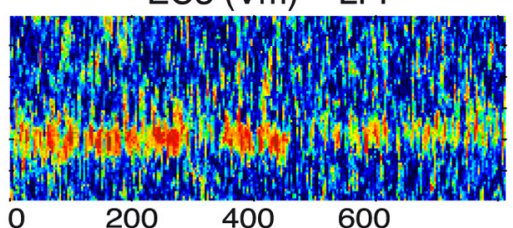

LFP (EC3)

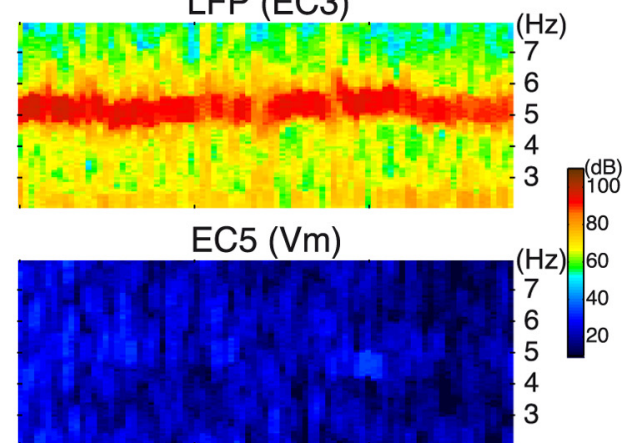

EC5 (Vm) - LFP

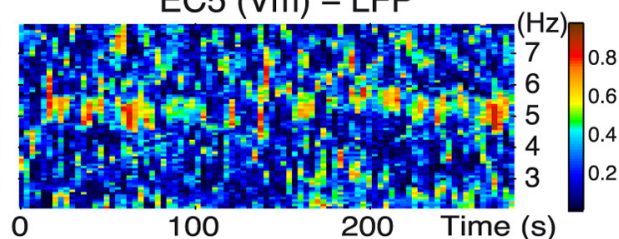

B Power Coherence EC2 $(\mathrm{Vm})$-LFP Power Coherence EC3 $(\mathrm{Vm})$-LFP
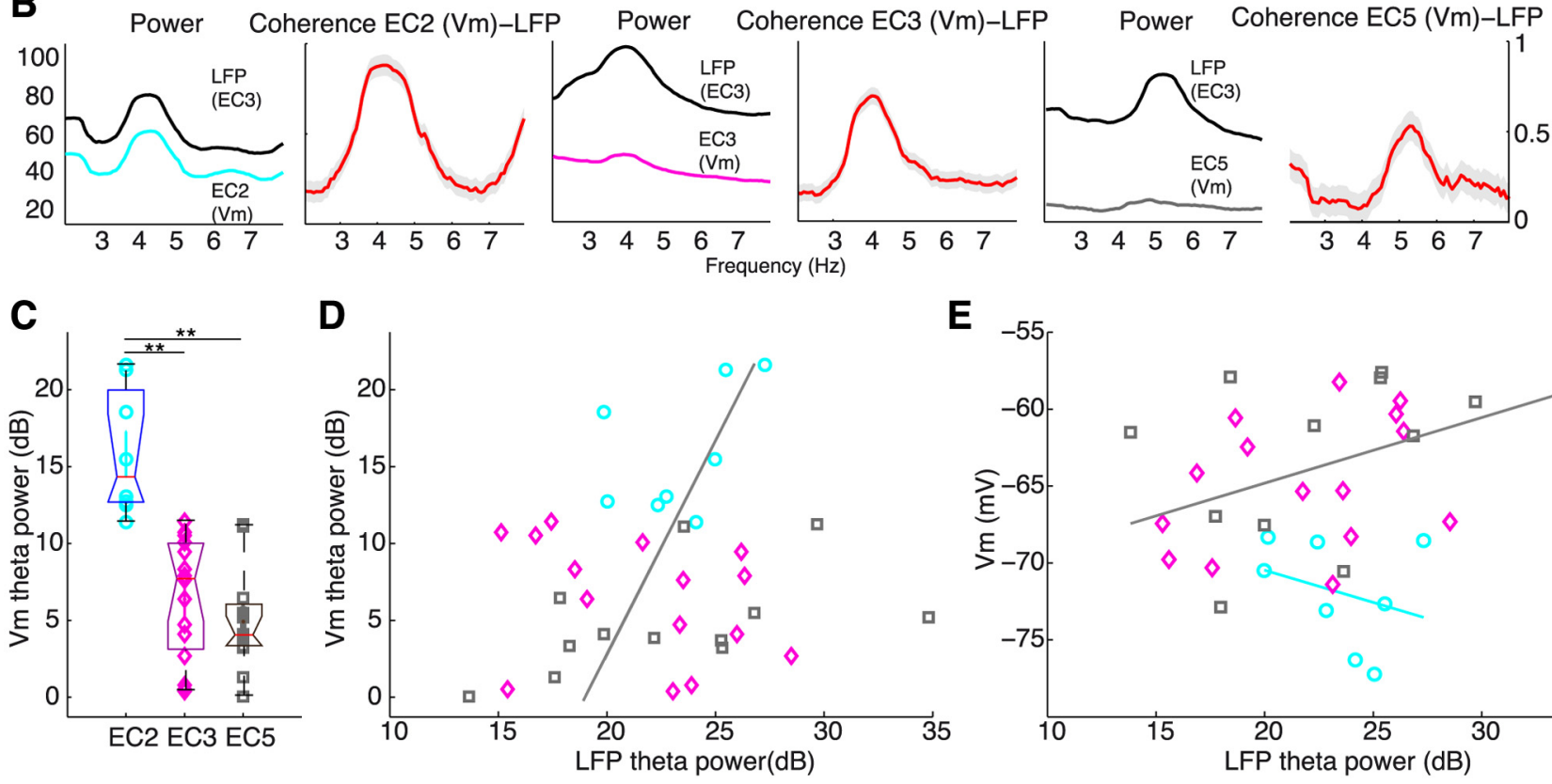

G
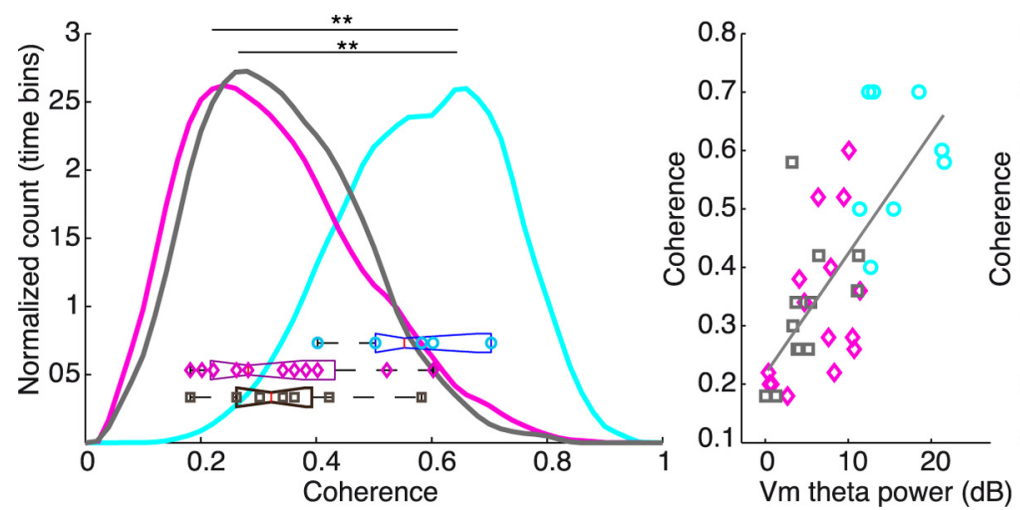

H
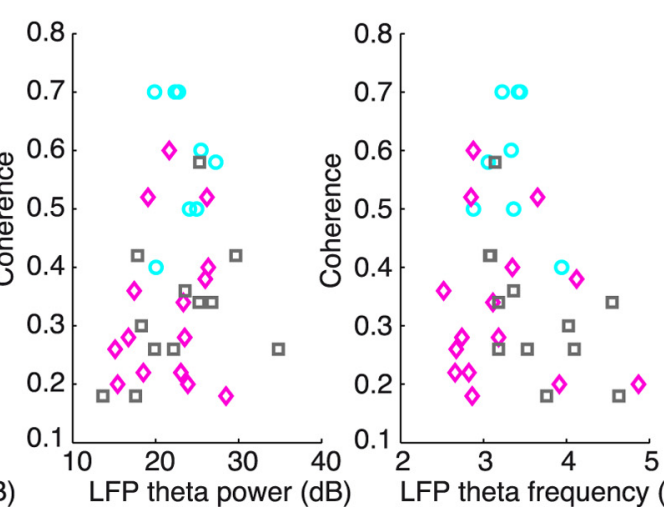

LFP theta power $(\mathrm{dB}) \quad$ LFP theta frequency $(\mathrm{Hz})$

Figure 5. Contribution of EC neurons to LFP theta. $A$, Relationship between LFP (in EC3, top row) and membrane potential $\left(V_{m}\right)$ in example EC2, EC3, and EC5 neurons (middle row) during theta oscillations. Bottom row, Coherence between LFP and $V_{m} \cdot \boldsymbol{B}$, Power and coherence spectra for the respective neurons. $C$, Theta power of the membrane potential $\left(V_{m}\right)$ fluctuation, normalized by the theta power of the LFP (**p $<0.002)$. D, Relationship between LFP and $V_{m}$ theta power. $\boldsymbol{E}$, Relationship between LFP theta power and mean "resting" $V_{m}$. $\boldsymbol{F}$, Distribution of within-session coherence, measured in 3 s segments ( 1 s vererlap, ${ }^{* *} p<0.005$ ). The mean group coherence values are shown by the box plots. $\mathbf{G}-\mathbf{I}$, Theta coherence as a function of intracellular theta power $(\mathbf{G})$, LFP theta power $(\boldsymbol{H})$, and theta frequency $(\boldsymbol{I})$. 
A



B

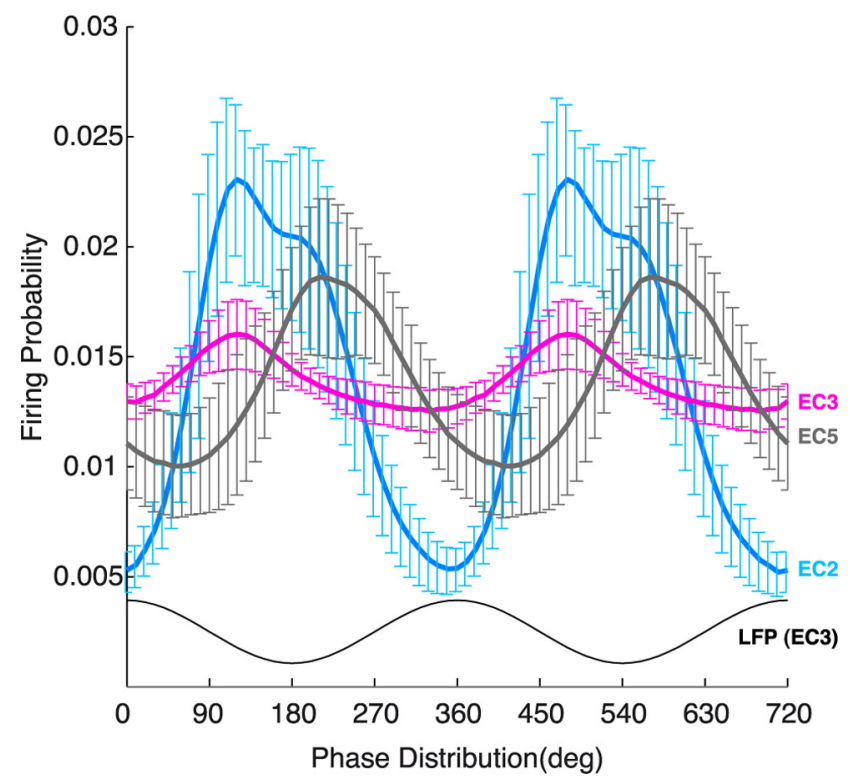

Figure 6. Theta oscillations in intracellularly identified EC neurons. $\boldsymbol{A}$, Polar plots of preferred phase and modulation depth (mean resultant length; line) of EC2, EC3, and EC5 neuron intracellular (IC) spikes referenced to theta oscillation in EC3 (filled symbols). Phase difference and coherence between the membrane potential $\left(V_{\mathrm{m}}\right.$; open symbols) and LFP (peak of theta $=0$, $360^{\circ}$; trough $=180^{\circ}$ ) is shown for all neurons. $\boldsymbol{B}$, Population discharge probability of intracelIularly identified principal neurons from different subregions as a function of EC3 theta phase (gray trace). Two theta cycles are shown to facilitate visual comparison. Bin size, $10^{\circ}$. Note strongest theta modulation in EC2 neurons.

in EC1 is an indication of inward current, possibly induced by the recurrent collaterals of EC2 neurons terminating on the apical dendrites of EC cells. The origin of S2 and S3 is less clear because their magnitude and position showed more variability across different experiments (supplemental Fig. 3, available at www. jneurosci.org as supplemental material). As expected from the power and phase depth profiles of gamma oscillations, the largest sink-source pair of gamma was present at the EC1-EC2 border, with only weak additional sinks in deeper layers. These observations sug- gest that, although all principal cell types participate in the generation of LFP theta, EC2 neurons provide the strongest theta dipoles.

Theta phase modulation of extracellularly recorded neurons

The layer identity of the extracellularly recorded neurons was assisted by the layer-specific LFP patterns (Mizuseki et al., 2009). Units recorded at the border of layers with ambiguous layer identity were discarded. Because we could not routinely distinguish between EC5 and EC6 layers with our methods, they were lumped together as EC5. Extracellularly recorded neurons contain both principal cells and interneurons. Because the intracellularly recorded and identified neurons revealed large variations in the firing rates and autocorrelogram patterns even within the same group (supplemental Fig. 3, available at www.jneurosci.org as supplemental material) and because previous works indicated that these parameters are not reliable predictors of neuron type identity in the EC (Mizuseki et al., 2009), we took advantage of the simultaneously recorded EC cells to identify the recorded units as excitatory or inhibitory neurons by their short-latency temporal interactions with other neurons (Barthó et al., 2004; Sirota et al., 2008; Mizuseki et al., 2009). Putative monosynaptic connections were associated with precisely timed spiking relationships at short $(<5 \mathrm{~ms})$ latency offsets between two recorded neurons, as illustrated by the narrow, short-latency peak or trough in the cross-correlogram (Fig. 8A,B) (Mizuseki et al., 2009). We also found inhibitory connections between putative interneuron-intracellularly recorded cell pairs $(n=2)$, with mean unitary IPSPs of $\sim 0.1 \mathrm{mV}$ (Fig. $8 C$ ). The time course of the IPSP, superimposed on the large theta-associated $V_{\mathrm{m}}$, corresponded to the time course of spike suppression. These putative monosynaptic connections allowed the reconstruction of functional subnetworks in different layers of the EC (Fig. $8 E$ ). In two experiments, we found putative excitatory connections between excitatory EC2 neurons (a pair is shown in Fig. 8 E; pair 1 and 2). Although we did not find excitatory monosynaptic connections between intracellularly identified neurons and extracellularly recorded units (but see Marshall et al., 2002), current-induced action potentials in two neurons reliably altered local network activity, as reflected by the complex, multisynaptic effects they evoked (Fig. 8 F) (Szabadics et al., 2006).

Using the above criteria, we identified 196 putative principal cells and 260 interneurons from the total of 1100 unit clusters and used them for additional analysis. Note that the cross-correlation identification method is biased in favor of finding more inhibitory interneurons because of the stronger connections between interneurons and principal cells than among principal cells (Barthó et al., 2004).

To examine the spike-theta phase relationship of extracellularly recorded neurons, we used two complementary measures: the distribution of preferred phases of single neurons (Fig. $9 A, C, D, F)$ and theta phase distribution of all the spikes in the population (Fig. 9B,E). As in the waking rat (Chrobak and Buzsáki, 1998; Hafting et al., 2008; Mizuseki et al., 2009), EC2 neurons showed strong phase-locking to the trough of EC3 LFP theta (Stewart et al., 1992) and contained the highest fraction of significantly theta-modulated neurons (Fig. $9 A-D$ ). In contrast, the EC3 principal cell group contained only a small fraction of significantly modulated cells, and individual EC3 principal cells showed a wide range of theta phase preferences. As a result, the putative EC3 principal cells were least modulated by the theta cycle as a population. The EC2 and EC3 populations fired on the opposite phases of theta (Fig. 9B,C). Phase preference of putative EC5 principal cells was also variable (Chrobak and Buzsáki, 1994, 1998; Frank et al., 2001; Mizuseki et al., 2009). This situation is 
different from the waking animal, in which EC3 neurons fire coherently on the same phase of theta, whereas EC2 principal cells have an activity-dependent distribution on a wide range of phases (Mizuseki et al., 2009). These firing pattern differences may contribute to the different depth profiles of theta oscillations in the hippocampus in waking and anesthetized rats (supplemental Fig. 2, available at www.jneurosci.org as supplemental material). The physiologically identified inhibitory interneuron groups in all layers tended to fire at the same phase (near the EC3 theta trough and on the ascending phase), with the EC2 group showing the strongest theta modulation (Fig. 9D-F; $p<$ 0.005, ANOVA), and were silenced together at approximately the same theta phase. In EC5, a minority of relatively well modulated interneurons fired at either the trough or on the ascending phase. In summary, the extracellulary recorded units in various EC layers showed similar phase preference and proportionally similar magnitude of theta modulation as the intracellularly identified subsets of EC2, EC3, and EC5 neurons.

\section{Gamma modulation of EC neurons}

To study the contribution of various neuron types to gamma oscillations, the wideband trace was bandpass filtered (30-90 $\mathrm{Hz}$ ) and the troughs of the gamma waves were detected. Spikes were referenced to the phase of local gamma detected by the adjacent electrode site on the same shank. EC3 principal cells showed the strongest phase-locking to the descending phase of the local LFP gamma, followed by EC2 and EC5 principal cells (Fig. 10A-C). Interneurons in EC2, EC3, and EC5 showed approximately the same magnitude of gamma phase modulation and lagged $45-60^{\circ}$ after the respective principal cell population (Fig. $10 D-F$ ). Gamma phase-locking of units in different layers, referenced to a common EC3 LFP gamma, is shown in supplemental Figure 4 (available at www.jneurosci.org as supplemental material).

The magnitude of intracellular gamma-associated $V_{\mathrm{m}}$ change was small relative to theta $V_{\mathrm{m}}$ oscillations in all cases $(30-300$ $\mu \mathrm{V}$ ) (Fig. 11A). Gamma power of $V_{\mathrm{m}}$ with a distinct peak was observed in only two EC2 and two EC3 neurons (an example is shown Fig. $11 B$, arrow). To improve the gamma-to-noise ratio in $V_{\mathrm{m}}$, we generated spike-triggered averages of $V_{\mathrm{m}}$, triggered by the physiologically identified inhibitory neurons (Matsumura et al., 1996). These spike-triggered $V_{\mathrm{m}}$ averages revealed IPSPs superimposed on the intracellular theta signal and time-locked to the spikes of the putative interneurons (Fig. $11 D$ ). The intervals of the IPSPs $(20-40 \mathrm{~ms})$ corresponded to the mean frequency of the simultaneously recorded LFP gamma (Fig. $11 D$, arrows).

Theta phase modulation of gamma and high-frequency power The comodulation of theta and gamma power is illustrated in Figure 10C (arrow). The power of both gamma oscillations and frequency bands.
B

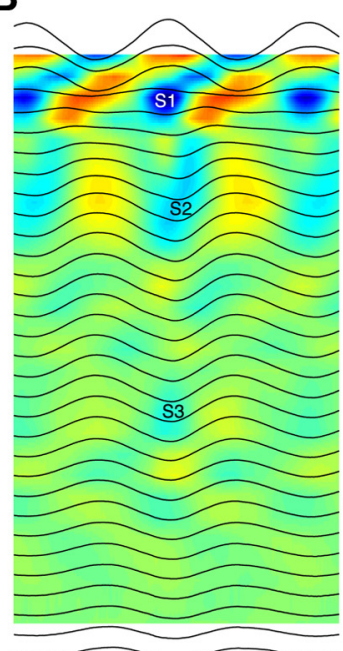

C

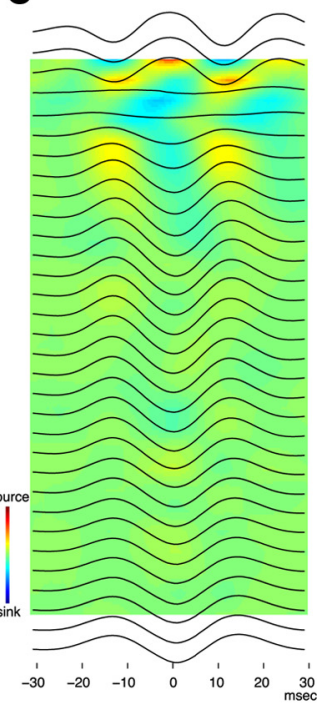

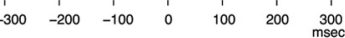
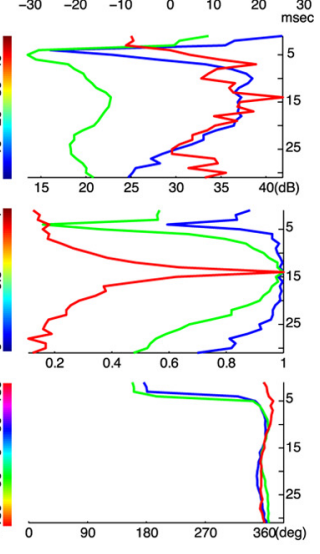

10 Frequency $(\mathrm{Hz})$

100

600
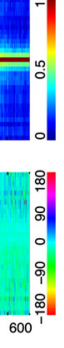

Figure 7. Depth profiles of EC LFP patterns. $A$, Short epoch (2s) of LFP (1 Hz to $5 \mathrm{kHz}$ ) recorded by a 32-site, single-shank silicon Color-coded depth profile maps of power (whitened spectra see Materials and Methods) coherence (relative to EC $\mathrm{LFP}$. arrow), and phase of LFP (note log frequency scale). Theta $(2-5 \mathrm{~Hz})$, gamma $(30-60 \mathrm{~Hz})$, and high-frequency $(200-600 \mathrm{~Hz})$ bands are marked by blue, green, and red dashed lines, respectively. Right, Power, coherence, and depth profiles of the three marked

the high-frequency band was modulated by the phase of theta oscillations in each layer (Fig. $11 E, F)$. The theta phase relationship of gamma power $(30-90 \mathrm{~Hz})$ allowed for additional separation of EC1-EC2 and deeper layer gamma oscillations. Gamma power in the superficial layers was largest right after the EC3 theta peak, whereas EC3 gamma power was maximal on the late descending part. In all layers, including EC5, gamma power had a minimum on the ascending phase of EC3 theta (Fig. $11 E$ ), coinciding with the phase of least interneuronal activity (Fig. $10 D-F$ ). In contrast, the high-frequency power was locked to the trough of EC3 theta (Fig. $11 \mathrm{~F}$ ), in which most spiking activity was present (Figs. 9, 10). These findings indicate that, similar to the hippocampus (Bragin et al., 1995; Csicsvari et al., 2003; Montgomery and Buzsáki, 2007), gamma oscillations can be generated locally in each EC layer and that these oscillations are coordinated by the phase of hippocampal theta rhythm (Chrobak and Buzsáki, 1998).

\section{Discussion}

We found that EC5 and EC2 principal neurons form extensive local networks, interconnected by the more vertically organized (“columnar") EC3 pyramidal cells. Principal cells in these layers 
A

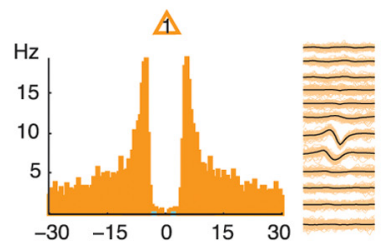

(2)

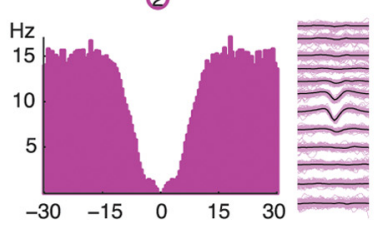

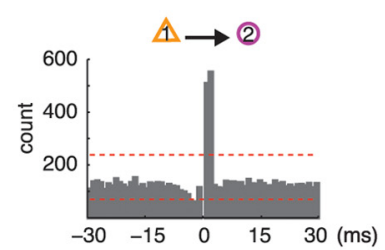

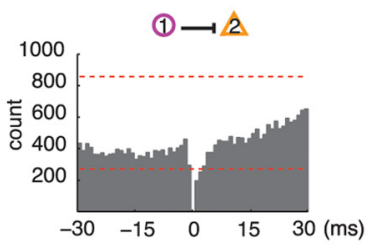

C
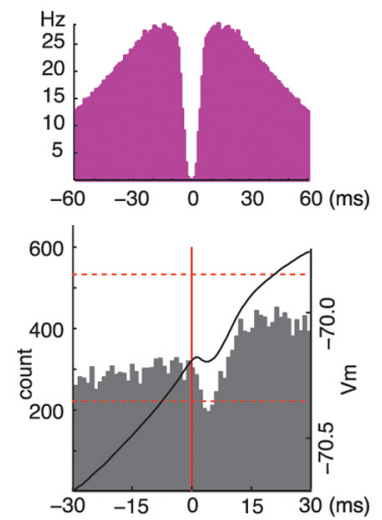

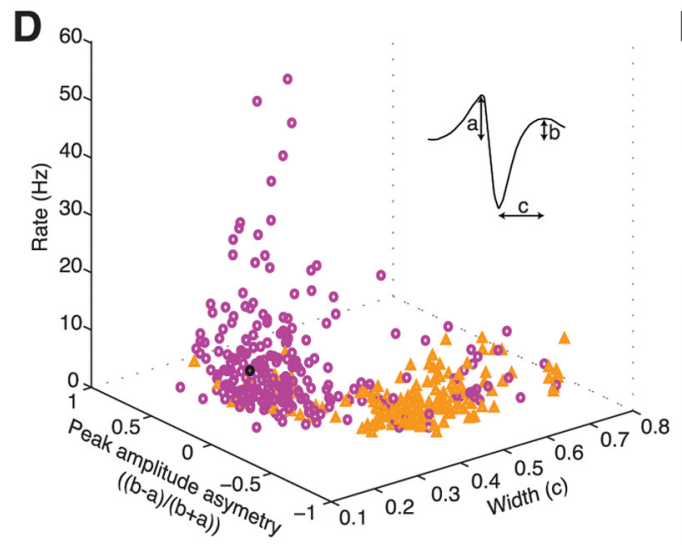

F EC2-Interneuron
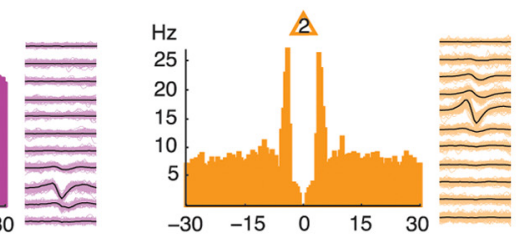

E
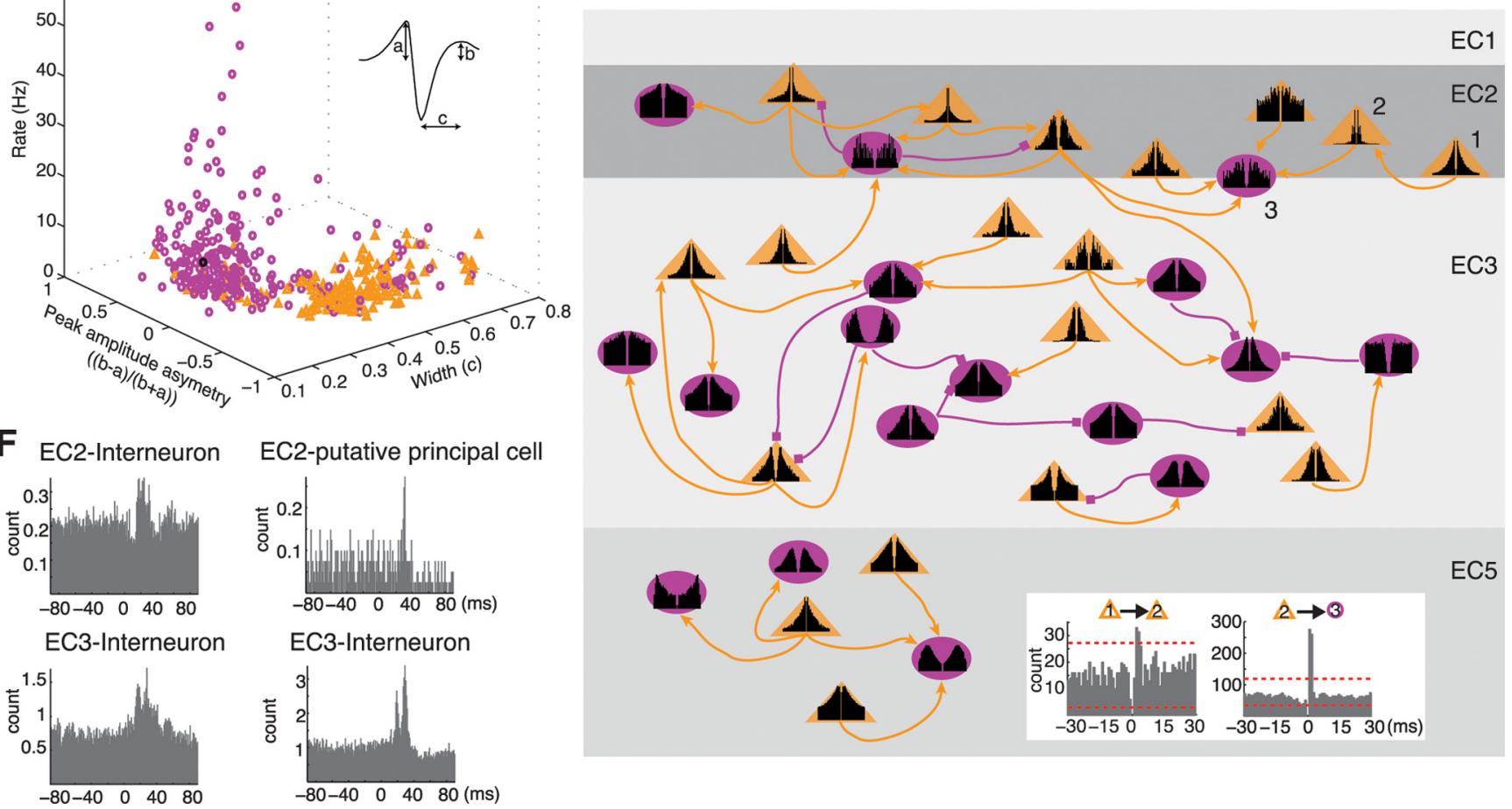

Figure 8. Physiological identification of putative EC principal cells and interneurons. A, Autocorrelograms and average filtered ( $0.8-5 \mathrm{kHz})$ waveforms of a putative EC2 principal cell (yellow) and an EC2 interneuron (purple). Abscissa indicates milliseconds. Right, Cross-correlogram revealed short-latency monosynaptic excitation between neuron 1 and neuron 2 (dashed lines indicate 1 and $99 \%$ global confidence intervals estimated by spike jittering on a uniform interval of $[-5,5] \mathrm{ms}$ ) (Fujisawa et al., 2008). B, Same display as in $\boldsymbol{A}$ but for an EC(3 interneuron-principal cell pair. Note short-latency suppression of spikes in the target principal neuron. C, Monosynaptic inhibitory connection between a putative EC3 interneuron and intracellularly recorded and histologically verified EC3 pyramidal cell. Top, Autocorrelogram of the inhibitory interneuron. Bottom, Cross-correlogram between the spikes of the reference interneuron and pyramidal cell. The spike-triggered average of $V_{\mathrm{m}}$ of the pyramidal cell (black line; $n=94,221$ events) is superimposed on the cross-correlogram. Note short-latency hyperpolarization on the rising phase of the intracellular theta oscillation. $D$, Physiologically identified principal cells (yellow triangles; $n=196$ ) and interneurons (purple circles; $n=260$ ) as a function of waveform asymmetry, trough-to-peak latency (width; see inset; $0.8-5 \mathrm{kHz}$ ) (Sirota et al., 2008; Mizuseki et al., 2009), and firing rate (see Materials and Methods). Note that single-cell features alone do not provide perfect separation of principal cells and interneurons. $E$, Putative subnetworks of the physiologically identified neurons in a single experiment. Triangle, Principal cell; oval, interneuron; arrow, putative excitatory connection; square, inhibitory connection. The autocorrelogram of each neuron is shown within symbols. Note cross-layer pairs between putative principal cells and interneurons in EC2 and EC3. Note also putative excitatory connections between EC2 principal cells ( 1 and 2, for instance). Cross-correlogram identifies the presynaptic cell as excitatory ( 1 and 2 ). The monosynaptically driven postsynaptic neuron of the pair is also excitatory as shown by its cross-correlation with another neurons (putative interneuron 3). $\boldsymbol{F}$, Network effects induced by a single neuron. Discharge of an EC2 or EC3 principal cell evoked long-latency, presumably multisynaptically mediated, firing patterns in target neurons.

have unique membrane properties and differentially contribute to theta and gamma oscillations. EC2 stellate cells are strongly phase-locked to theta and tuned to resonate at theta frequency. LFP gamma oscillations are largest in the superficial layers and modulated by the phase of theta waves. In contrast to the distinct firing patterns of principal cells, interneurons in all EC layers fire synchronously on the same phase.
Connectivity of the principal cells in the EC

Although the number of intracellularly labeled neurons in our study was limited, certain tentative conclusions from their axonal arbors can be made. EC5 neurons may contribute three and five times more intrinsic connections than EC2 and EC3 neurons, respectively. Both EC5 and EC2 neurons have extensive connections in both mediolateral and frontocaudal directions (Amaral 
and Witter, 1989; Lingenhöhl and Finch, 1991; Tamamaki and Nojyo, 1993; Jones, 1994; Klink and Alonso, 1997; Dolorfo and Amaral, 1998a,b; Hamam et al., 2000; Gloveli et al., 2001), whereas axon collaterals of EC3 neurons are more restricted spatially (Germroth et al., 1989; Lingenhöhl and Finch, 1991). EC5 neurons form a coneshaped axon arbor with its base in EC5 and its peak in EC2. This arrangement suggests that EC5 cells communicate mainly with their peers within the same layer through the basal dendrites and with progressively fewer neurons in EC3 toward the surface, contributing few axons to EC2-EC1 (van Haeften et al., 2003; Kloosterman et al., 2003, 2004). The axon cloud of EC2 stellate cells is an inverted cone with its wide base in EC1 and peak at the EC3-EC5 border. Assuming that connectivity follows the distribution of the available target neurons, the broad and dense axon collaterals of EC2 stellate cells in EC1 indicates that they form connections with the apical dendrites of both superficial and deep layer principal cells in a wide cylinder. Therefore, EC2 stellate cells can address a wide array of EC2, EC3, and EC5 neurons. The divergent-convergent EC2-EC3-EC2 recurrent loop may be instrumental in segregating neurons both spatially and temporally. In contrast, EC5 pyramidal cells would influence only very few superficial neurons directly, indicating a strongly asymmetric divergent-convergent communication between EC2 and EC5 principal cells. The axons of EC3 cells form a relatively narrow barrel with most axon terminals ending in EC3 and progressively less in deeper and more superficial layers (Germroth et al., 1989; Lingenhöhl and Finch, 1991). Such distribution of axon collaterals suggests that EC3 neurons provide the critical bidirectional conduit between superficial and deep layers so that the inputs from both EC2 and EC5 can activate many EC3 neurons, whereas the EC3 outputs converge on smaller subsets of EC2 and/or EC5 cells, restricting the spatial spread of excitatory activity from deep to superficial layers (Kloosterman et al., 2003, 2004). Embedded in this excitatory web reside a variety of interneuron families, whose connectivity is poorly understood. Furthermore, there might be variations of connectivity within each layer, adding more computational power to the circuits (Canto et al., 2008).

The special architecture of the EC must have important implications for its functional operations. Generation of the grid pattern in EC2 neurons is believed to be dependent on attractor dynamics supported by recurrent networks (McNaughton et al., et al., 2009).
A

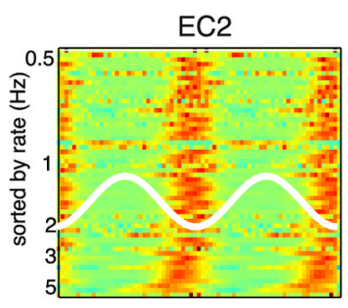

B

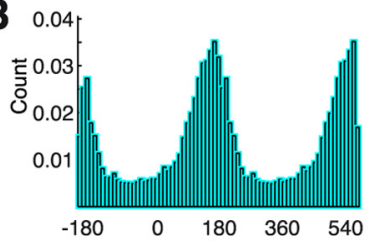

C

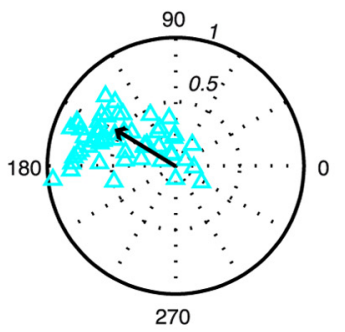

D

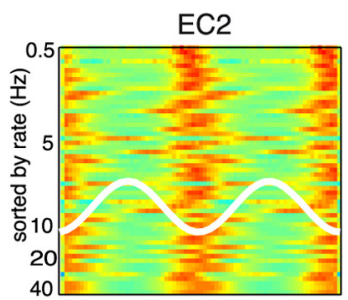

E



$\mathbf{F}$



Principal cells

EC3
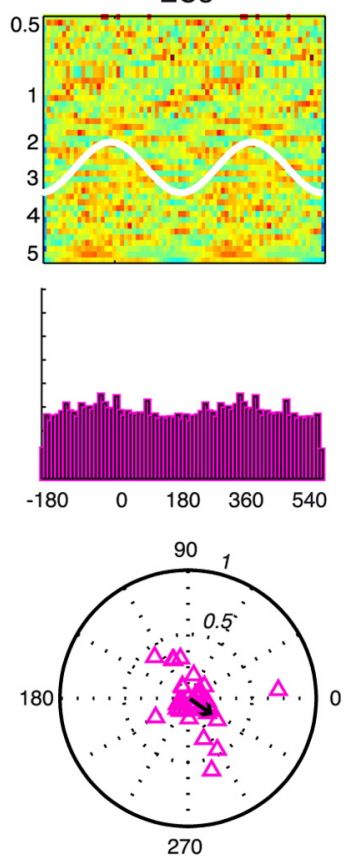

Interneurons

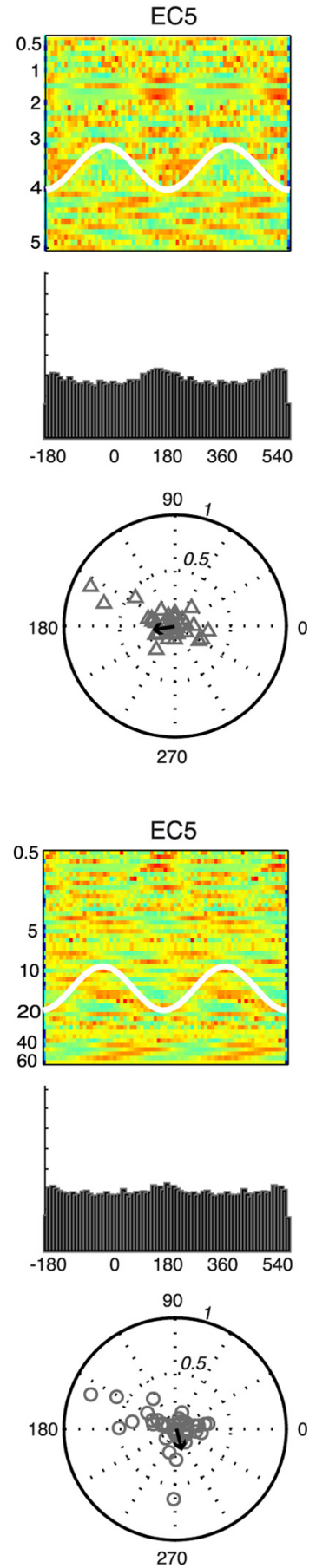

Figure 9. Theta phase modulation of EC neurons. $\boldsymbol{A}$, Color-coded discharge probability of physiologically identified, extracellularly recorded EC2 $(n=54)$, EC3 $(n=43)$, and EC5 $(n=40)$ principal cells as a function of EC3 theta phase (white line). Each row is a single neuron, normalized to its peak firing rate $(r e d=1)$. Neurons are sorted according to firing rate (left axis). Only neurons with at least 50 spikes, firing rate $>0.5 \mathrm{~Hz}$, and significant theta modulation (Rayleigh test, $p<0.01$ ) are included. $\boldsymbol{B}$, Population discharge probability of the EC principal neuron groups shown in $\boldsymbol{A}$. All neurons are included. Bin size, $10^{\circ}$. C, Polar plots of preferred phase and theta modulation depth of single neurons (symbols) and group mean (black arrows). $\boldsymbol{D}-\boldsymbol{F}$, Same display as $\boldsymbol{A}-\boldsymbol{C}$ for physiologically identified EC2 ( $n=56), \mathrm{EC} 3(n=73)$, and EC5 $(n=49)$ interneurons. Note strongest theta phase modulation in EC2 principal neurons. Note also that EC2 and EC3 principal cells tend to fire at the opposite phase of the theta oscillations (Mizuseki

2006; Burgess et al., 2007; Hasselmo et al., 2007; Hasselmo, 2008). Our findings support the existence of the postulated recurrent networks in EC2. EC2 neurons had very extensive axon collaterals in EC1, presumably contacting dendrites of principal cells of 
A
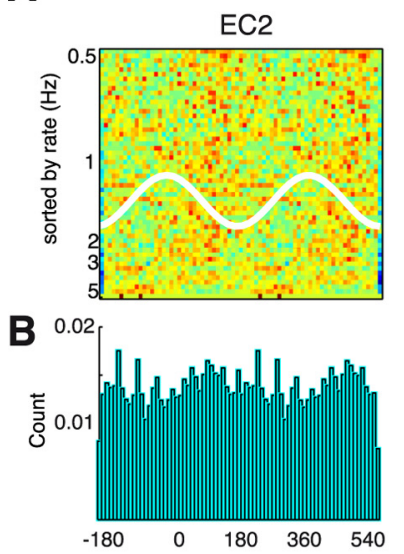

C

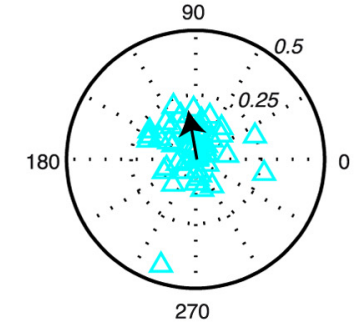

D

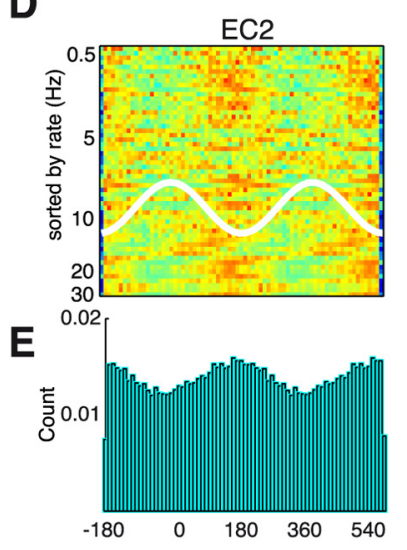

$\mathbf{F}$



Principal cells
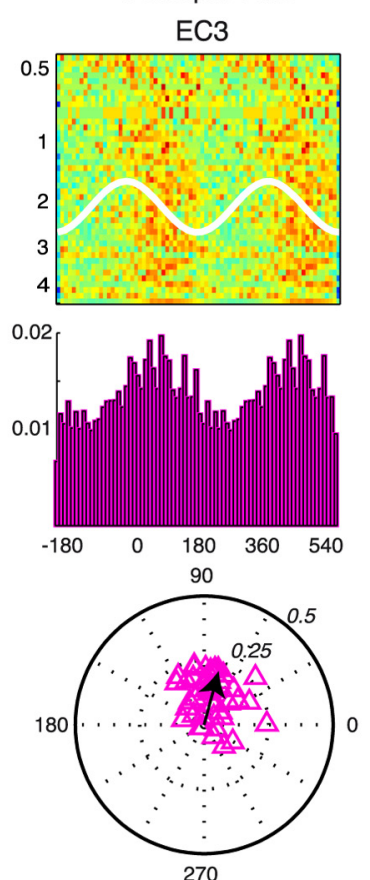

Interneurons

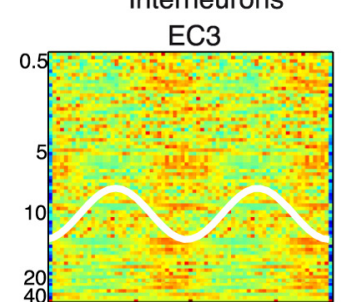

0.02
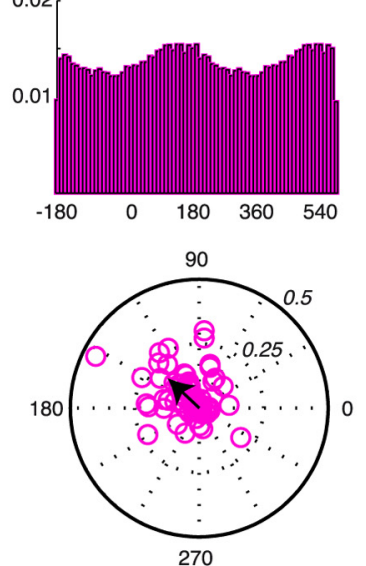


Figure 10. Gamma phase modulation of EC neurons. $A$, Color-coded discharge probability of physiologically identified, extracellularly recorded EC2, EC3, and EC5 ( $n=40)$ principal cells as a function of local gamma phase (white line). Each row is a single neuron, normalized to its peak firing rate (red $=1)$. Neurons are sorted according to firing rate (left axis). $\boldsymbol{B}$, Population discharge probability of the $\mathrm{EC}$ principal neuron groups shown in $\boldsymbol{A}$. All neurons are included, independent of whether their spikes were significantly modulated by gamma phase or not. Bin size, $10^{\circ}$. C, Polar plots of preferred phase and gamma modulation depth of single neurons (symbols) and group mean (black arrows). Only neurons with at least 50 spikes and firing rate $>0.5 \mathrm{~Hz}$ (Rayleigh test, $p<0.01)$ are included. $\boldsymbol{D}-\boldsymbol{F}$, Same display as $\boldsymbol{A}-\mathbf{C}$ for physiologically identified EC2 $(n=56)$, EC3 $(n=73)$, and EC5 $(n=49)$ interneurons. Note phase-delayed firing of interneurons relative to principal cells in all layers.

all layers. Although this claim should be supported by future electron microscopic data, the presence of recurrent connections is supported by our physiological evidence, showing monosynaptic connections between pairs of putative EC2 principal neurons. The lack of physiological connections between pairs of EC2 neurons in a previous study (Dhillon and Jones, 2000) could be explained by the strongly reduced axonal arborization in the slice preparation (M. Witter, personal communication). The postulated recurrent connections among EC5 neurons are supported by previous experiments (Lingenhöhl and Finch, 1991; Jones, 1994).

\section{Theta oscillations in the EC}

Although the current experiments were performed under anesthesia (see discussion of caveats in supplemental Fig. 2, available at www.jneurosci.org as supplemental material), a number of observations indicate the critical role of the EC circuits in theta oscillations. First, stellate cells are endowed with intrinsic properties that facilitates oscillation at theta frequency (Alonso and Llinás, 1989; Klink and Alonso, 1997; Dickson et al., 2000). A prominent sag ( $\mathrm{HCN} 1$ channel-mediated h current) (Alonso and Llinás, 1989; Giocomo et al., 2007) was present in all of the intracellularly recorded EC2 neurons but absent in other principal cells. Second, EC2 stellate cells showed the largest theta power and most coherent $V_{\mathrm{m}}$ oscillations with the extracellular LFP theta of all EC neurons. The low input impedance, coupled with large-amplitude thetaassociated $V_{\mathrm{m}}$ change in EC2 neurons compared with EC3 and EC5 cells, implies a strong theta-associated membrane current in stellate cells and hence several times larger contribution to the LFP theta than that of the other EC neurons. The theta behavior of $V_{\mathrm{m}}$ in EC cells can be contrasted to their activity during slow oscillations when the $V_{\mathrm{m}}$ of EC3 and EC5 neurons show prominent bimodality inphase with the LFP slow oscillation, whereas EC2 stellate cells rarely do so (Isomura et al., 2006). These observations suggest that the intrinsic properties of EC2 stellate neurons are tuned to resonate at theta frequency (Giocomo et al., 2007; Giocomo and Hasselmo, 2008). Third, EC2 stellate cells, as a group, behaved coherently, as shown by the narrow phase distribution of both $V_{\mathrm{m}}$ and spike preference of single EC2 neurons during theta oscillation. In contrast, pyramidal cells in both EC3 and EC5 had a large variability of theta phase preference. Finally, theta amplitude was largest in EC1, a layer to which EC2 neurons contribute the most axon collaterals and boutons.

The largest-amplitude theta waves in EC1, the layer containing the distal apical dendritic arbor of EC principal cells, are reminiscent of the similarly largest theta power in the CA1 stratum lacunosum-moleculare (Kamondi et al., 1998). The phase reversal of theta waves above the cell bodies of EC2 cells, again 

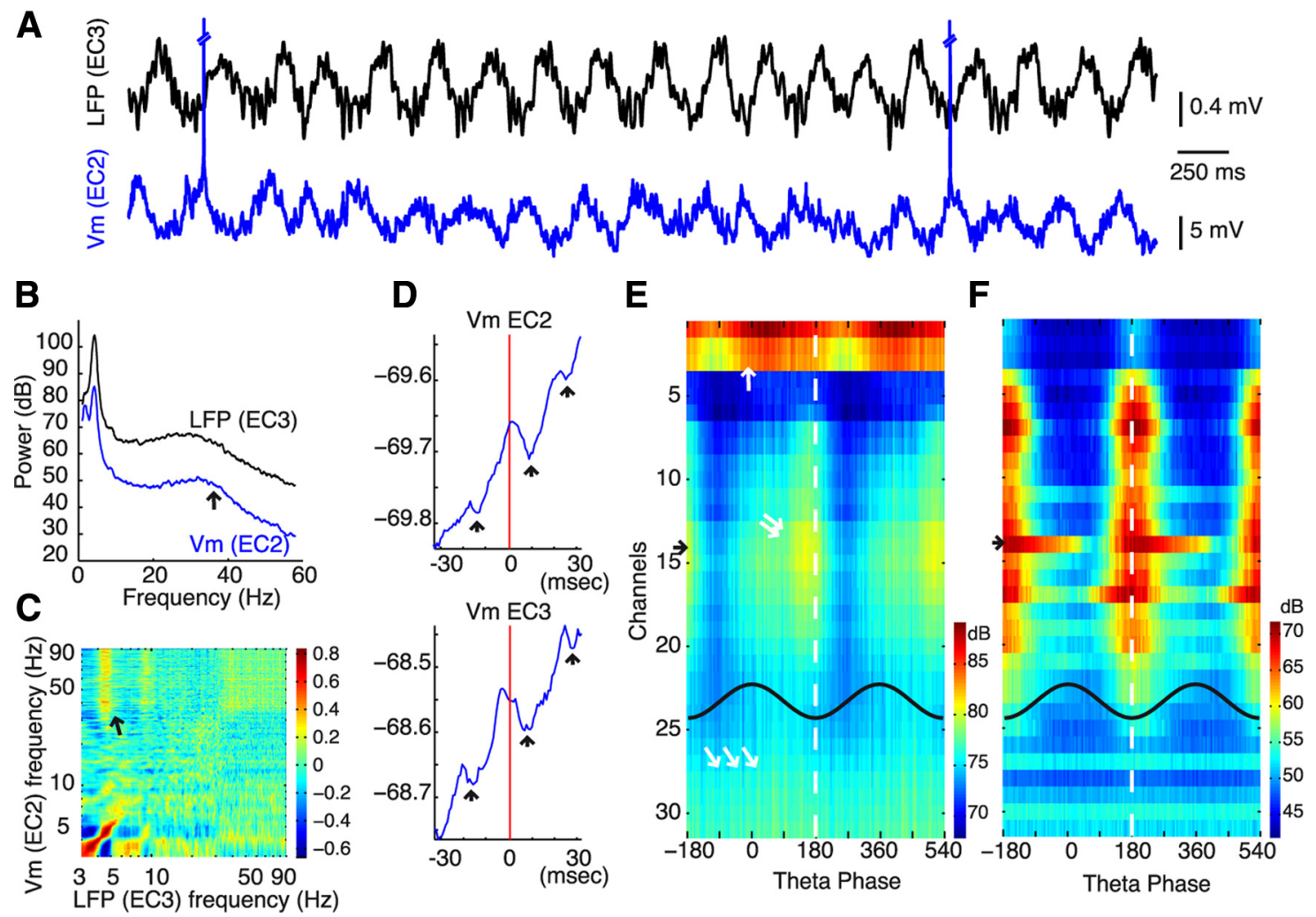

Figure 11. Theta phase modulation of gamma power. $A$, Short epoch ( $5 \mathrm{~s}$ ) of LFP in EC3 (1 Hz to $1.25 \mathrm{kHz})$ and $V_{\mathrm{m}}$ of an $\mathrm{EC} 2$ stellate cell with the strongest theta modulation. Note theta and faster gamma waves in $V_{\mathrm{m}}$. Spikes are clipped. $\boldsymbol{B}$, Power spectra of LFP and $V_{\mathrm{m}}$. Arrow, Intracellular gamma band activity. C, Power-power correlation (comodugram) between LFP and $V_{\mathrm{m}}$. Note strong power-power coupling at theta frequency $(4.5 \mathrm{~Hz})$ and LFP theta modulation of EC2 $V_{\mathrm{m}}$ gamma power (arrow; note log scale). D, Average $V_{\mathrm{m}}$ in EC2 and EC3 neurons triggered by spikes of physiologically identified interneurons. Zero milliseconds is the time of the reference interneuron spike (each trace is an average of 1419 and 2702 events). Arrows indicate IPSPs at gamma frequency superimposed on the larger-amplitude theta-related $V_{m} . E$, Theta phase modulation of integrated LFP gamma power $(30-90 \mathrm{~Hz}$; color coded) as a function of recording depth (recording sites $1-32$ of the silicon probe). Horizontal arrow, Theta phase reference site (recording site 14 in EC3; black trace). Single, double, and triple arrows, Peaks of EC1/EC2, EC3, and EC5 gamma power, respectively. $\boldsymbol{F}$, Theta phase modulation of high-frequency $(>200 \mathrm{~Hz})$ power. Note the phase-locking of power to the trough of EC3 theta and high-frequency power in EC2-EC3.

similar to CA1 pyramidal cells (Winson, 1974), can be explained by inhibitory sources on the large cell bodies of EC2 stellate neurons (Brankack et al., 1993). Voltage-gated $\mathrm{Ca}^{2+}$ spikes in the apical tufts of EC2 and/or EC3-EC5 neurons can further amplify the synapse-mediated sinks in EC1, similar to the distal dendrites of CA1 pyramidal neurons (Kamondi et al., 1998). Overall, the dedicated theta generation mechanisms and special loop connectivity (putative EC2-EC2; E2-EC3-EC2) lend support to the hypothesized mechanisms underlying grid pattern formation in EC2 cells (Samsonovich and McNaughton, 1997; Fuhs and Touretzky, 2006; McNaughton et al., 2006; Moser and Moser, 2008).

\section{Gamma oscillations in the EC}

Gamma oscillations in the EC and their interactions with hippocampal gamma (Charpak et al., 1995; Chrobak and Buzsáki, 1998; Colgin et al., 2009) are assumed to support basic operations at the EChippocampal interface, including learning and memory (Fell et al., 2001, 2002; Steinvorth et al., 2010). Gamma oscillations in the EC may arise from multiple mechanisms (Cunningham et al., 2003, 2004, 2006; Middleton et al., 2008). In agreement with in vitro studies (Cunningham et al., 2003; Middleton et al., 2008), we found that gamma oscillations independently emerged in different layers. The largest-amplitude gamma oscillations were observed in EC1-EC2, with a null zone and abrupt phase reversal between EC1 and EC2 (Chrobak et al., 1998). The absence of well defined gamma dipoles in the other layers may be attributable to the extensive vertical disper- sion of principal cell bodies and the temporal variation of shortlasting gamma bursts in the various layers (Sirota et al., 2008). The distinct nature of layer-specific gamma oscillations was also demonstrated by the theta phase modulation of gamma power, with EC2 gamma power peaking on the descending theta phase, followed by EC3 and EC5 gamma oscillations at later phases. The spatial and temporal segregation of EC gamma rhythms may engage different regions of the hippocampus in a task-specific manner (Charpak et al., 1995; Chrobak and Buzsáki, 1998; Middleton et al., 2008; Colgin et al., 2009).

Overall, maximum gamma power coincided with the descending phase of EC3 theta and preceded the maximum discharge of the principal cells. It is notable that a similar phase relationship exists in the hippocampal CA1 region (Bragin et al., 1995; Buzsáki et al., 2003), implying a general mechanism. The temporal delay between gamma power maximum and the maximum probability of spiking may serve two purposes. First, the gamma-related hyperpolarization of the $V_{\mathrm{m}}$ may effectively lower the spike threshold by erasing the spiking history-dependent reduction of the available $\mathrm{Na}^{+}$channels (Spruston et al., 1995; Henze and Buzsáki, 2001). Second, the release of the $V_{\mathrm{m}}$ from transient hyperpolarization can facilitate "rebound" spiking (Cobb et al., 1995), which may be particularly effective in neurons with prominent $I_{\mathrm{h}}$ (Alonso and Klink, 1993; Giocomo et al., 2007). How the different EC gamma generators interact with layer-specific gamma rhythms in the hippocampus and 
serve various aspects of behavior remains a challenge for future experiments.

\section{References}

Alonso A, García-Austt E (1987a) Neuronal sources of theta rhythm in the entorhinal cortex of the rat. I. Laminar distribution of theta field potentials. Exp Brain Res 67:493-501.

Alonso A, García-Austt E (1987b) Neuronal sources of theta rhythm in the entorhinal cortex of the rat. II. Phase relations between unit discharges and theta field potentials. Exp Brain Res 67:502-509.

Alonso A, Klink R (1993) Differential electroresponsiveness of stellate and pyramidal-like cells of medial entorhinal cortex layer II. J Neurophysiol 70:128-143.

Alonso A, Llinás RR (1989) Subthreshold $\mathrm{Na}^{+}$-dependent theta-like rhythmicity in stellate cells of entorhinal cortex layer II. Nature 342:175-177.

Amaral DG, Witter MP (1989) The three-dimensional organization of the hippocampal formation: a review of anatomical data. Neuroscience 31:571-591.

Barthó P, Hirase H, Monconduit L, Zugaro M, Harris KD, Buzsáki G (2004) Characterization of neocortical principal cells and interneurons by network interactions and extracellular features. J Neurophysiol 92:600-608.

Blair HT, Gupta K, Zhang K (2008) Conversion of a phase- to a rate-coded position signal by a three-stage model of theta cells, grid cells, and place cells. Hippocampus 18:1239-1255.

Bragin A, Jandó G, Nádasdy Z, Hetke J, Wise K, Buzsáki G (1995) Gamma $(40-100 \mathrm{~Hz})$ oscillation in the hippocampus of the behaving rat. J Neurosci 15:47-60.

Brankack J, Stewart M, Fox SE (1993) Current source density analysis of the hippocampal theta rhythm: associated sustained potentials and candidate synaptic generators. Brain Res 615:310-327.

Burak Y, Fiete IR (2009) Accurate path integration in continuous attractor network models of grid cells. PLoS Comput Biol 5:e1000291.

Burgess N, Barry C, O'Keefe J (2007) An oscillatory interference model of grid cell firing. Hippocampus 17:801-812.

Burwell RD (2000) The parahippocampal region: corticocortical connectivity. Ann N Y Acad Sci 911:25-42.

Buzsáki G, Eidelberg E (1983) Phase relations of hippocampal projection cells and interneurons to theta activity in the urethane anesthetized rat. Brain Res 266:334-339.

Buzsáki G, Leung LW, Vanderwolf CH (1983) Cellular bases of hippocampal EEG in the behaving rat. Brain Res 287:139-171.

Buzsáki G, Czopf J, Kondákor I, Kellényi L (1986) Laminar distribution of hippocampal rhythmic slow activity (RSA) in the behaving rat: currentsource density analysis, effects of urethane and atropine. Brain Res 365:125-137.

Canolty RT, Edwards E, Dalal SS, Soltani M, Nagarajan SS, Kirsch HE, Berger MS, Barbaro NM, Knight RT (2006) High gamma power is phaselocked to theta oscillations in human neocortex. Science 313:1626-1628.

Canto CB, Wouterlood FG, Witter MP (2008) What does the anatomical organization of the entorhinal cortex tell us? Neural Plast 2008:381243.

Charpak S, Paré D, Llinás R (1995) The entorhinal cortex entrains fast CA1 hippocampal oscillations in the anaesthetized guinea-pig: role of the monosynaptic component of the perforant path. Eur J Neurosci 7: $1548-1557$.

Chrobak JJ, Buzsáki G (1994) Selective activation of deep layer (V-VI) retrohippocampal cortical neurons during hippocampal sharp waves in the behaving rat. J Neurosci 14:6160-6170.

Chrobak JJ, Buzsáki G (1998) Gamma oscillations in the entorhinal cortex of the freely behaving rat. J Neurosci 18:388-398.

Cobb SR, Buhl EH, Halasy K, Paulsen O, Somogyi P (1995) Synchronization of neuronal activity in hippocampus by individual GABAergic interneurons. Nature 378:75-78.

Colgin LL, Denninger T, Fyhn M, Hafting T, Bonnevie T, Jensen O, Moser MB, Moser EI (2009) Frequency of gamma oscillations routes flow of information in the hippocampus. Nature 462:353-357.

Csicsvari J, Hirase H, Czurkó A, Mamiya A, Buzsáki G (1999) Oscillatory coupling of hippocampal pyramidal cells and interneurons in the behaving rat. J Neurosci 19:274-287.

Csicsvari J, Jamieson B, Wise KD, Buzsáki G (2003) Mechanisms of gamma oscillations in the hippocampus of the behaving rat. Neuron 37:311-322.

Cunningham MO, Davies CH, Buhl EH, Kopell N, Whittington MA (2003)
Gamma oscillations induced by kainate receptor activation in the entorhinal cortex in vitro. J Neurosci 23:9761-9769.

Cunningham MO, Halliday DM, Davies CH, Traub RD, Buhl EH, Whittington MA (2004) Coexistence of gamma and high-frequency oscillations in rat medial entorhinal cortex in vitro. J Physiol 559:347-353.

Cunningham MO, Hunt J, Middleton S, LeBeau FE, Gillies MJ, Davies CH, Maycox PR, Whittington MA, Racca C (2006) Region-specific reduction in entorhinal gamma oscillations and parvalbumin-immunoreactive neurons in animal models of psychiatric illness. J Neurosci 26:2767-2776.

Dhillon A, Jones RS (2000) Laminar differences in recurrent excitatory transmission in the rat entorhinal cortex in vitro. Neuroscience 99:413-422.

Dickson CT, Mena AR, Alonso A (1997) Electroresponsiveness of medial entorhinal cortex layer III neurons in vitro. Neuroscience 81:937-950.

Dickson CT, Magistretti J, Shalinsky MH, Fransén E, Hasselmo ME, Alonso A (2000) Properties and role of $\mathrm{I}(\mathrm{h})$ in the pacing of subthreshold oscillations in entorhinal cortex layer II neurons. J Neurophysiol 83:2562-2579.

Dickson CT, Biella G, de Curtis M (2003) Slow periodic events and their transition to gamma oscillations in the entorhinal cortex of the isolated guinea pig brain. J Neurophysiol 90:39-46.

Dolorfo CL, Amaral DG (1998a) Entorhinal cortex of the rat: topographic organization of the cells of origin of the perforant path projection to the dentate gyrus. J Comp Neurol 398:25-48.

Dolorfo CL, Amaral DG (1998b) Entorhinal cortex of the rat: organization of intrinsic connections. J Comp Neurol 398:49-82.

Fell J, Klaver P, Lehnertz K, Grunwald T, Schaller C, Elger CE, Fernández G (2001) Human memory formation is accompanied by rhinalhippocampal coupling and decoupling. Nat Neurosci 4:1159-1160.

Fell J, Klaver P, Elger CE, Fernández G (2002) The interaction of rhinal cortex and hippocampus in human declarative memory formation. Rev Neurosci 13:299-312.

Fisher NI (1993) Statistical analysis of circular data. Cambridge, UK: Cambridge UP.

Frank LM, Brown EN, Wilson MA (2001) A comparison of the firing properties of putative excitatory and inhibitory neurons from CA1 and the entorhinal cortex. J Neurophysiol 86:2029-2040.

Freeman JA, Nicholson C (1975) Experimental optimization of current source-density technique for anuran cerebellum. J Neurophysiol 38:369382.

Fuhs MC, Touretzky DS (2006) A spin glass model of path integration in rat medial entorhinal cortex. J Neurosci 26:4266-4276.

Fujisawa S, Amarasingham A, Harrison MT, Buzsáki G (2008) Behaviordependent short-term assembly dynamics in the medial prefrontal cortex. Nat Neurosci 11:823-833.

Germroth P, Schwerdtfeger WK, Buhl EH (1989) Morphology of identified entorhinal neurons projecting to the hippocampus. A light microscopical study combining retrograde tracing and intracellular injection. Neuroscience 30:683-691.

Giocomo LM, Hasselmo ME (2008) Time constants of $h$ current in layer II stellate cells differ along the dorsal to ventral axis of medial entorhinal cortex. J Neurosci 28:9414-9425.

Giocomo LM, Hasselmo ME (2009) Knock-out of HCN1 subunit flattens dorsal-ventral frequency gradient of medial entorhinal neurons in adult mice. J Neurosci 29:7625-7630.

Giocomo LM, Zilli EA, Fransén E, Hasselmo ME (2007) Temporal frequency of subthreshold oscillations scales with entorhinal grid cell field spacing. Science 315:1719-1722.

Gloveli T, Dugladze T, Schmitz D, Heinemann U (2001) Properties of entorhinal cortex deep layer neurons projecting to the rat dentate gyrus. Eur J Neurosci 13:413-420.

Hafting T, Fyhn M, Molden S, Moser MB, Moser EI (2005) Microstructure of a spatial map in the entorhinal cortex. Nature 436:801-806.

Hafting T, Fyhn M, Bonnevie T, Moser MB, Moser EI (2008) Hippocampus-independent phase precession in entorhinal grid cells. Nature 453:1248-1252.

Hamam BN, Kennedy TE, Alonso A, Amaral DG (2000) Morphological and electrophysiological characteristics of layer $\mathrm{V}$ neurons of the rat medial entorhinal cortex. J Comp Neurol 418:457-472.

Harris KD, Henze DA, Hirase H, Leinekugel X, Dragoi G, Czurkó A, Buzsáki G (2002) Spike train dynamics predicts theta-related phase precession in hippocampal pyramidal cells. Nature 417:738-741.

Hasselmo ME (2008) Grid cell mechanisms and function: contributions of 
entorhinal persistent spiking and phase resetting. Hippocampus 18: 1213-1229.

Hasselmo ME, Giocomo LM, Zilli EA (2007) Grid cell firing may arise from interference of theta frequency membrane potential oscillations in single neurons. Hippocampus 17:1252-1271.

Hazan L, Zugaro M, Buzsáki G (2006) Klusters, NeuroScope, NDManager: a free software suite for neurophysiological data processing and visualization. J Neurosci Methods 155:207-216.

Henze DA, Buzsáki G (2001) Action potential threshold of hippocampal pyramidal cells in vivo is increased by recent spiking activity. Neuroscience 105:121-130.

Henze DA, Borhegyi Z, Csicsvari J, Mamiya A, Harris KD, Buzsáki G (2000) Intracellular features predicted by extracellular recordings in the hippocampus in vivo. J Neurophysiol 84:390-400.

Isomura Y, Sirota A, Ozen S, Montgomery S, Mizuseki K, Henze DA, Buzsáki G (2006) Integration and segregation of activity in entorhinal-hippocampal subregions by neocortical slow oscillations. Neuron 52:871-882.

Jeewajee A, Barry C, O'Keefe J, Burgess N (2008) Grid cells and theta as oscillatory interference: electrophysiological data from freely moving rats. Hippocampus 18:1175-1185.

Jones RS (1994) Synaptic and intrinsic properties of neurons of origin of the perforant path in layer II of the rat entorhinal cortex in vitro. Hippocampus 4:335-353.

Kamondi A, Acsády L, Wang XJ, Buzsáki G (1998) Theta oscillations in somata and dendrites of hippocampal pyramidal cells in vivo: activitydependent phase-precession of action potentials. Hippocampus 8:244-261

Klink R, Alonso A (1997) Morphological characteristics of layer II projection neurons in the rat medical entorhinal cortex. Hippocampus 7:571-583.

Kloosterman F, Van Haeften T, Witter MP, Lopes Da Silva FH (2003) Electrophysiological characterization of interlaminar entorhinal connections: an essential link for re-entrance in the hippocampal-entorhinal system. Eur J Neurosci 18:3037-3052.

Kloosterman F, van Haeften T, Lopes da Silva FH (2004) Two reentrant pathways in the hippocampal-entorhinal system. Hippocampus 14:10261039.

Lingenhöhl K, Finch DM (1991) Morphological characterization of rat entorhinal neurons in vivo: soma-dendritic structure and axonal domains. Exp Brain Res 84:57-74.

Logothetis NK (2003)MR imaging in the non-human primate: studies of function and of dynamic connectivity. Curr Opin Neurobiol 13:630-642.

Marshall L, Henze DA, Hirase H, Leinekugel X, Dragoi G, Buzsáki G (2002) Hippocampal pyramidal cell-interneuron spike transmission is frequency dependent and responsible for place modulation of interneuron discharge. J Neurosci 22:RC197(1-5).

Matsumura M, Chen D, Sawaguchi T, Kubota K, Fetz EE (1996) Synaptic interactions between primate precentral cortex neurons revealed by spike-triggered averaging of intracellular membrane potentials in vivo. J Neurosci 16:7757-7767.

McNaughton BL, Battaglia FP, Jensen O, Moser EI, Moser MB (2006) Path integration and the neural basis of the "cognitive map." Nat Rev Neurosci $7: 663-678$

Middleton S, Jalics J, Kispersky T, Lebeau FE, Roopun AK, Kopell NJ, Whittington MA, Cunningham MO (2008) NMDA receptor-dependent switching between different gamma rhythm-generating microcircuits in entorhinal cortex. Proc Natl Acad Sci U S A 105:18572-18577.

Mitchell SJ, Ranck JB Jr (1980) Generation of theta rhythm in medial entorhinal cortex of freely moving rats. Brain Res 189:49-66.

Mitra PP, Pesaran B (1999) Analysis of dynamic brain imaging data. Biophys J 76:691-708.

Mizuseki K, Sirota A, Pastalkova E, Buzsáki G (2009) Theta oscillations provide temporal windows for local circuit computation in the entorhinalhippocampal loop. Neuron 64:267-280.

Montgomery SM, Buzsáki G (2007) Gamma oscillations dynamically couple hippocampal CA3 and CA1 regions during memory task performance. Proc Natl Acad Sci U S A 104:14495-14500.

Mormann F, Fell J, Axmacher N, Weber B, Lehnertz K, Elger CE, Fernández G (2005) Phase/amplitude reset and theta-gamma interaction in the human medial temporal lobe during a continuous word recognition memory task. Hippocampus 15:890-900.

Moser EI, Moser MB (2008) A metric for space. Hippocampus 18: $1142-1156$.

Moser EI, Kropff E, Moser MB (2008) Place cells, grid cells, and the brain's spatial representation system. Annu Rev Neurosci 31:69-89.

Nunez PL, Srinivasan R (2006) A theoretical basis for standing and traveling brain waves measured with human EEG with implications for an integrated consciousness. Clin Neurophysiol 117:2424-2435.

Ranck JB Jr (1985) Head direction cells $n$ the deep cell layer of dorsal postsubicculum in freely moving rats. In: Electrical activity of the archicortex (Buzsáki G, Vanderwolf CH, eds), pp 217-220. Budapest: Akademiai Kiado.

Samsonovich A, McNaughton BL (1997) Path integration and cognitive mapping in a continuous attractor neural network model. J Neurosci 17:5900-5920.

Sargolini F, Fyhn M, Hafting T, McNaughton BL, Witter MP, Moser MB, Moser EI (2006) Conjunctive representation of position, direction, and velocity in entorhinal cortex. Science 312:758-762.

Sirota A, Montgomery S, Fujisawa S, Isomura Y, Zugaro M, Buzsáki G (2008) Entrainment of neocortical neurons and gamma oscillations by the hippocampal theta rhythm. Neuron 60:683-697.

Solstad T, Boccara CN, Kropff E, Moser MB, Moser EI (2008) Representation of geometric borders in the entorhinal cortex. Science 322:18651868.

Spruston N, Schiller Y, Stuart G, Sakmann B (1995) Activity-dependent action potential invasion and calcium influx into hippocampal CAl dendrites. Science 268:297-300.

Squire LR (2004) Memory systems of the brain: a brief history and current perspective. Neurobiol Learn Mem 82:171-177.

Steinvorth S, Wang C, Ulbert I, Schomer D, Halgren E (2010) Human entorhinal gamma and theta oscillations selective for remote autobiographical memory. Hippocampus 20:166-173.

Stewart M, Quirk GJ, Barry M, Fox SE (1992) Firing relations of medial entorhinal neurons to the hippocampal theta rhythm in urethane anesthetized and walking rats. Exp Brain Res 90:21-28.

Suzuki WA, Amaral DG (2004) Functional neuroanatomy of the medial temporal lobe memory system. Cortex 40:220-222.

Szabadics J, Varga C, Molnár G, Oláh S, Barzó P, Tamás G (2006) Excitatory effect of GABAergic axo-axonic cells in cortical microcircuits. Science 311:233-235.

Tamamaki N, Nojyo Y (1993) Projection of the entorhinal layer II neurons in the rat as revealed by intracellular pressure-injection of neurobiotin. Hippocampus 3:471-480.

Taube JS (1995) Place cells recorded in the parasubiculum of freely moving rats. Hippocampus 5:569-583.

van der Linden S, Lopes da Silva FH (1998) Comparison of the electrophysiology and morphology of layers III and II neurons of the rat medial entorhinal cortex in vitro. Eur J Neurosci 10:1479-1489.

van Haeften T, Baks-te-Bulte L, Goede PH, Wouterlood FG, Witter MP (2003) Morphological and numerical analysis of synaptic interactions between neurons in deep and superficial layers of the entorhinal cortex of the rat. Hippocampus 13:943-952.

Van Hoesen GW, Pandya DN (1975) Some connections of the entorhinal (area 28) and perirhinal (area 35) cortices of the rhesus monkey. III. Efferent connections. Brain Res 95:39-59.

Winson J (1974) Patterns of hippocampal theta in the freely moving rat. Electroencephalogr Clin Neurophysiol 36:291-301.

Witter MP, Moser EI (2006) Spatial representation and the architecture of the entorhinal cortex. Trends Neurosci 29:671-678. 